\title{
Data report: core-log-seismic integration and time-depth relationships at IODP Expedition 341 Southern Alaska Margin Sites U1420 and U1421, Bering Trough, Gulf of Alaska'
}

\author{
Wesley A. Clary, ${ }^{2}$ Lindsay L. Worthington, ${ }^{2}$ Angela L. Slagle, ${ }^{3}$ and Hugh Daigle ${ }^{4}$
}

\section{Chapter contents}

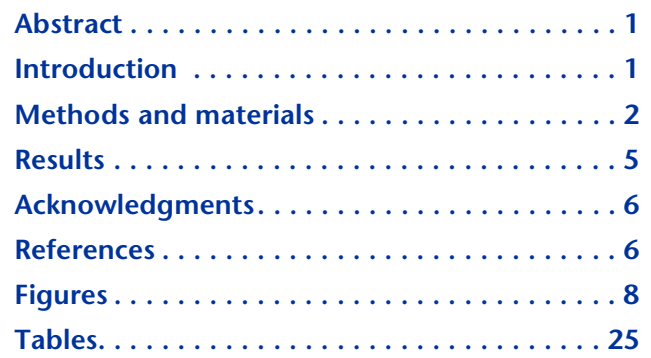

${ }^{1}$ Clary, W.A., Worthington, L.L., Slagle, A.L., and Daigle, H., 2017. Data report: core-log-seismic integration and time-depth relationships at IODP Expedition 341 Southern Alaska Margin Sites U1420 and U1421, Bering Trough, Gulf of Alaska. In Jaeger, J.M., Gulick, S.P.S., LeVay, L.J., and the Expedition 341 Scientists, Proceedings of the Integrated Ocean Drilling Program, 341: College Station, TX (Integrated Ocean Drilling Program). doi:10.2204/iodp.proc.341.204.2017

${ }^{2}$ Department of Earth and Planetary Sciences, University of New Mexico, 221 Yale Boulevard NE, Albuquerque NM 87131-0001, USA.

Correspondence author: wesclary@unm.edu ${ }^{3}$ Lamont-Doherty Earth Observatory, Columbia University, 212A Borehole, Palisades NY 109648000, USA.

${ }^{4}$ Department of Petroleum and Geosystems Engineering, University of Texas, 200 East Dean Keeton Street, Stop C0300, Austin TX 787121585 , USA.

\begin{abstract}
We present a time-depth relationship for Integrated Ocean Drilling Program (IODP) Expedition 341 Southern Alaska Margin Sites U1420 and U1421 using high-resolution multichannel seismic, core, and logging data. Calibrating and combining core and logging data at each site minimizes data gaps in physical properties information. Remaining data gaps were interpolated using spline fitting in order to provide continuous estimates of bulk density and compressional wave velocity for the full drilled interval. We use the interpolated physical property curves for bulk density and compressional wave velocity at each site to generate synthetic seismic traces. At Site U1421, vertical seismic profiling further constrained the time-depth relationship and was used to calibrate the velocity curve and provide input for the initial velocity model during the tie. Finally, we matched simulated reflectors in the synthetic trace with events in the nearby seismic traces and established a time-depth relationship at each site.
\end{abstract}

\section{Introduction}

A major goal of Integrated Ocean Drilling Program (IODP) Expedition 341 Southern Alaska Margin was investigation of interrelationships between tectonic processes, paleoclimate, and glacial activity. One of the primary expedition research questions focuses on if and how large-scale mass redistribution through rapid sedimentation or glacial advance and retreat can alter the geometry of tectonic wedges in a temperate glaciated margin (e.g., Berger et al., 2008; Worthington et al., 2010). High-resolution sequence stratigraphic and structural studies of the offshore sedimentary record are essential to establishing connections between tectonic deformation and glacial processes. Developing accurate chronological relationships requires careful calibration between seismic and well-derived data. Here, we focus on core-log-seismic integration of Sites U1420 and U1421 near the Bering Trough offshore southeast Alaska. Coring at these sites (Fig. F1) sampled sediments of the Pamplona fold and thrust belt, which has accommodated shortening during Yakutat microplate convergence with North America since $\sim 25 \mathrm{Ma}$ (Worthington et al., 2010). 
Constraining the rate, amount, and distribution, of sedimentation is important to evaluating regional hypotheses relating shelf development, tectonic activity, and paleoclimate variations. Well and logging data from Expedition 341 provides important stratigraphic, physical property, and age data recorded in depth which facilitates development of a constrained stratigraphic model that can be extended across the shelf if carefully integrated with local and regional seismic surveys. The challenging drilling environment resulted in limited core recovery due to large clasts and poorly consolidated material and difficult logging mostly due to borehole instability (see the "Site U1420" and "Site U1421" chapters [Jaeger et al., 2014b, 2014c]). These factors result in significant data gaps that present challenges with core-logseismic integration. We attempt to bridge data gaps by using aggressively fitted splines in constrained intervals where data coverage did not include significant gaps greater than $\sim 25 \mathrm{~m}$. In poorly constrained intervals, with gaps as large as $\sim 270 \mathrm{~m}$, we apply spline fits with a higher smoothness parameter (Silverman, 1985). The smoother splines typically fit the data less well in constrained intervals but result in more conservative estimates of variability where measurements are lacking. We used the continuous spline curves to generate synthetic seismograms at the site and matched the synthetic traces with highresolution seismic survey EW0408 Lines GOA 2503 and GOA 2505 according to traditional well-tie techniques (e.g., White, 1997; White and Simm, 2003). We used these time series and depth series matches to develop the final time-depth relationship (TDR) presented here that can be used to improve the calibration of developing age models. This study advances Expedition 341 scientific goals by providing a core-, log-, and seismic-constrained TDR for two sites on the southern Alaska shelf.

\section{Methods and materials}

\section{Physical property data}

Expedition 341 collected core and logging data on the continental shelf and slope at Sites U1420 and U1421 (Fig. F1). During drilling, the shipboard science party performed measurements of various physical properties at multiple scales and resolutions. After the core came on deck, the whole-round core passed through the Special Task Multisensor Logger (STMSL) where gamma ray attenuation (GRA) bulk density and magnetic susceptibility measurements were collected. After a period of temperature equilibration, the core was passed through the WholeRound Multisensor Logger (WRMSL), which recorded GRA bulk density, magnetic susceptibility, and compressional wave velocity (using the $P$-wave velocity logger [PWL]). Natural gamma ray (NGR) measurements were taken before the splitting the cores into working and archive halves. The archive half then passed through the Section Half Multisensor Logger (SHMSL) where reflection spectroscopy, colorimetry, magnetic susceptibility, and laser splitcore surface analyses were performed. From the working halves, point measurements of compressional wave velocity were taken with the $P$-wave caliper (PWC) instrument and discrete samples were collected for moisture and density (MAD) measurements, which consisted of bulk density, water content, porosity, and grain density. This process is described in detail in the "Methods" chapter (Jaeger et al., 2014a) and is schematically illustrated in Figure F2. Core recovery was hindered at both sites by large clasts that jammed recovery equipment and resulted in $139.91 \mathrm{~m}$ of recovered core $(14 \%)$ over the $1020.8 \mathrm{~m}$ interval at Site U1420 (see the "Site U1420" chapter [Jaeger et al., 2014b]). At Site U1421, three holes were drilled, with Hole U1421A reaching total penetration of 1432.4 mbsf (driller's seafloor depth $=729.7 \mathrm{~m}$ ), and total recovery from all holes at Site U1421 was $\sim 176 \mathrm{~m}$.

At Sites U1420 and U1421, shipboard scientists deployed a wireline tool string, which included NGR, sonic velocity, and resistivity tools (see the "Site U1420" and "Site U1421" chapters [Jaeger et al., $2014 b, 2014 c])$. As a result of concerns about borehole stability during logging, the density tool with its radioactive source was not included in this tool string; thus, no in situ density measurements were made at Sites U1420 and U1421. The logged interval, excluding the bottom-hole assembly (BHA), at Site U1420 was 89-288 m wireline log matched depth below seafloor (WMSF) due to borehole instability (see the "Site U1420" chapter [Jaeger et al., 2014b]). At Site U1421, the logged interval was below the BHA at $92 \mathrm{~m}$ WMSF and extended to $695 \mathrm{~m}$ WMSF. At Site U1421, we used vertical seismic profile (VSP) constraints from six stations in the borehole to constrain the TDR between 1.278-1.641 s two-way traveltime (TWT) and 284.7-687 m WMSF (Table T1).

More details about core handling, logging data collection, and processing methods as well as tool string and instrument technical data can be found in the "Methods" chapter (Jaeger et al., 2014a). Table T2 summarizes site data including location and physical properties measurement availability by source. Logging summaries and plots are shown in Figure F3. Depth scales and datums are described in "Stratigraphic correlation" in the "Methods" chapter (Jaeger et al., 2014a). We approached the well tie process based on the methods of White and Simm (2003) in 
a few steps, including the development of initial velocity models, synthetic seismic generation, wavelet extraction, generation of a new synthetic seismic trace, and finally, conservative visual seismic-to-synthetic matching.

\section{Data conditioning and compilation}

In general our strategy was to favor a log-centric approach to the data conditioning for two reasons: (1) the core data seemed to be noisy and had more outliers in comparison to the logging data and (2) we expect the in situ logged values to be more consistent with conditions reflected in the seismic data than measurements derived post situ. Core-based and in situ logging data may be different for a number of reasons, such as sampling rate, measurement depth of investigation, datum mismatch, borehole and core irregularity, and coring practices (e.g., see the "Methods" chapter [Jaeger et al., 2014a] and Daigle and Piña, 2016). For the purposes of this study, we applied minimal or no specific corrections for such factors in preparing the data compilations. Shipboard core-based measurements were collected in a variety of methods including track-based sensors, which measure properties of the whole or splitcore; by analysis of discrete volumetric samples; and by using point-based instruments. Instrument response functions, the effects of core recovery technique (advanced piston coring [APC], extended core barrel [XCB], etc.), and a volumetric-based correction are discussed in Walczak et al. (2015). At Sites U1418 and U1417, the correction applied by Walczak et al. (2015) corrected for sediment compaction, variable recovered core diameter, and changes in the gas content of the sediment column but reduced the variance of NGR and bulk density measurements by $\sim 20 \%$ and $50 \%$, respectively, and after correction the largest changes in GRA bulk density were correlated with changes in coring technique. In order to preserve variability in the final synthetic seismic traces, our compilation treated all core-based data with equal weight and without adjustment for instrument effects or core recovery technique.

\section{Site $\mathrm{U} 1420$ density and velocity compilation}

At Site U1420, the bulk density data we included in the compilation were derived from WRMSL measurements where outliers $\left(<1 \mathrm{~g} / \mathrm{cm}^{3}\right)$ were removed from the data set and then smoothed by a 19-sample moving average; typically this resulted in a moving window of $45 \mathrm{~cm}$. STMSL bulk density data were not available at this site, but these measurements were at a lower spatial resolution than WRMSL GRA bulk density measurements, used similar sensors, were not given time for temperature equilibration, and were generally used for guiding drilling operations during the expedition (see the "Methods" chapter [Jaeger et al., 2014a]). Velocity data consisted of a logged interval with the Dipole Shear Sonic Imager (DSI) and PWC core measurements. We cleaned the PWC data of outlier measurements $<1.5 \mathrm{~km} / \mathrm{s}$. We compiled log data on the WMSF depth scale, which is based on matching a spike in the gamma ray log with the seafloor. Core data were compiled on the core depth below seafloor, Method A (CSF-A), depth scale, which is an initial scale based on the advancement of the drill string during coring (see "Stratigraphic correlation" in the "Methods" chapter [Jaeger et al., 2014a]). Core-based CSF-A and logging WMSF depth scales were used together directly, which may introduce error because of a number of drilling effects (see the "Methods" chapter [Jaeger et al., 2014a]), which we also discuss briefly here.

\section{Site U1421 density and velocity compilation}

At Site U1421, we compiled bulk density data from core for the STMSL, WRMSL sources, and from Holes U1421A-U1421C, which we cleaned of outliers beyond 2 standard deviations of the mean for each instrument source. Next, we culled any remaining measurements $<1 \mathrm{~g} / \mathrm{cm}^{3}$. Finally, we smoothed these compiled density data with a 19-sample moving average $(45 \mathrm{~cm})$ on the core composite depth below seafloor, Method B (CCSF-B), depth scale, which was developed by splicing Holes U1421A-U1421C accounting for ship heave and applying an affine value to adjust for postrecovery expansion (see "Stratigraphic correlation" in the "Methods" chapter [Jaeger et al., 2014a]). Compressional wave velocity data at Site U1421 included both core and logging data. We combined core-based velocity measurements from the PWL, WRMSL, and PWC on the CCSF-B depth scale. The sonic log was used on the WMSF depth scale, and after removal of outliers beyond 3 standard deviations from the moving $40 \mathrm{~m}$ average, we combined it with the core-based measurements, which were shifted so that their mean was equal to the mean value from logging data in the overlapping interval. This shift to the core measurements, an increase of $53 \mathrm{~m} / \mathrm{s}$, served as a simple method to calibrate the wireline-logged and core-derived measurements in such a way to approximate in situ logged measurements (Fig. F4).

\section{Data fitting}

In Matlab R2015a software, we fit the cleaned and processed data described above by spline approximations of various smoothness. We employed a strategy 
of aggressively fitting the data in constrained intervals, which tended to create artificial data variability and introduce unrealistic predictions, such as bulk density $<1 \mathrm{~g} / \mathrm{cm}^{3}$, or negative velocity estimates in unconstrained intervals. To overcome these artifacts of overfitting in large poorly constrained gaps and often also where the only source was core-based data, smoother splines were used for interpolation. To create data sets comparable to those generated in the logging operations and create continuous physical property records for the full drilled interval, we resampled the compiled smoothed data at $0.1524 \mathrm{~m}$ spacing, consistent with the logging rate. The final interpolated curves, goodness of fit characteristics, and original measurements are shown in Figures F5, F6, F7, F8, and F9 and discussed in Results.

\section{Initial velocity models}

At Site U1420, the initial velocity model was constructed directly from the compiled velocity curve, which included both logging and core data. We created initial interval velocity models for each site using the continuous velocity curves. The primary role of calibration at this site, as seen in Figure F10A, is to initially match the seafloor between the velocity curve, the seismic line (259 m WMSF and $330 \mathrm{~ms}$ TWT, respectively), and the interval velocity model at a $5 \mathrm{~m}$ sample spacing. At Site U1421, we used results from the VSP experiment to create an initial velocity structure against which to calibrate the velocity curve (Fig. F10B). We used the measured depth of the seafloor and the TWT of the positive seafloor arrival (729.7 $\mathrm{m}$ WMSF and $980 \mathrm{~ms}$, respectively) in the seismic line with the time-depth matches of the check shots (Table T3) to create the initial sevenlayer velocity model. In Petrel 2015 software, we performed calibration of the velocity curve to the VSP by addition of a linearly interpolated drift value between check shots as well as the interval velocity calculations.

\section{Synthetic seismic generation}

At each site, we iteratively generated a synthetic seismic trace; an initial convolution with calculated well reflectivity series and a Ricker wavelet provided a rough initial calibration. Next, any necessary bulk shift was applied to obtain a depth match between the seafloor in the drilling and seismic data. We used the Roy White wavelet extraction method at each site in Petrel 2015 to estimate source wavelet information using the continuous physical property curves and trace recordings near the hole. This method refines the tie by using cross-correlation of the hole reflectivity and seismic trace amplitudes to extract a deterministic wavelet (White, 1980). The algorithm produces a wavelet by using the ratio of cross-correlation of the reflectivity and seismic trace in the frequency domain (by fast Fourier transform) to the autocorrelation of reflectivity plus white noise. Spectral properties of wavelets used in this analysis are summarized in Figure F11. We convolved these deterministically extracted wavelets with the reflectivity series to create the synthetic seismic traces used in the synthetic-to-seismic matching process.

At Site U1420, we generated the synthetic seismic at the hole location first by convolution with the Ricker wavelet in Figure F11 (128 ms length and central positive peak at zero), and then any necessary bulk shift was applied to assure that the data aligned such that the seafloor time-depth match occurred near the positive seafloor reflection. Next, we performed convolution with a deterministically extracted wavelet (Fig. F11) according to the White method (White, 1980). Figure F12 shows the synthetic trace in the hole, nearby seismic traces from Line GOA 2505, interval velocity, and calculated reflection coefficients in both TWT and meters below sea level on the seismic depth scale (SSL). At Site U1421, we generated the synthetic seismic trace illustrated in Figure F13 using the deterministically extracted wavelet at this location after convolution with the same Ricker wavelet, as previously described, and bulk shift to maintain alignment of the top of the log with the positive reflection of the seafloor.

\section{Seismic-to-synthetic matching}

The traditional well tie method correlates the seismic recording and the synthetic seismic trace at the hole location (White, 1997). We made matches by visually identifying key horizons in the synthetic seismic trace generated in each hole and events in the survey near the hole location. In order to finally calibrate the hole and seismic, it is common practice to execute these matches by small adjustments to the velocity model in order to increase the correlation between the synthetic trace and the seismic data (White and Simm, 2003). In this way the velocity model, and thus the TDR, depends initially on the velocity $\log$, or velocity log and check shots in the case of Hole U1421A, and the final velocity model is determined by the applied adjustments from the visual matches (e.g., White and Simm, 2003). We applied the calibration procedure described above as the basis for the development of a TDR at each site (Tables T1, T4). 


\section{Results}

\section{Site U1420}

In Matlab R2015a we fitted four splines to the bulk density data for Site U1420, and based on the size of the data gap the splines were selectively sampled to create a continuous, partially interpolated record consistent with the sampling rate of typical logging (Fig. F3). We fit the upper $\sim 170 \mathrm{~m}$ with a spline achieving $R^{2}=0.800$ and root mean squared error (rmse) $=0.0746$ with the moving average of the data compilation in this region (Fig. F4). The data gap between 170 and 450 m CSF-A was interpolated with a minimum curvature spline, which was nearly equivalent to a linear fit between samples on either side of the gap. We fit the lower interval with an aggressive spline, which reached $R^{2}=0.8032$ and rmse $=0.0449$ deeper than $\sim 450 \mathrm{~m} \mathrm{CSF-A}$. For gaps near 500-550 and 700-750 m CSF-A, we interpolated with a smoother spline with a lower $R^{2}=0.38$ and rmse = 0.0842 compared to the data compilation. This selective sampling strategy resulted in conservative estimates of variability in poorly constrained intervals.

We created the continuous $P$-wave velocity curve from a compilation of logged and core-derived measurements where CSF-A and WMSF depth scales were used together directly. This may introduce error because in the CSF-A scale drilling effects such as core expansion caused by overburden release, compression during coring, and coring method are not compensated; these effects are typically on the order of $10 \%-20 \%$ (see "Stratigraphic correlation" in the "Methods" chapter [Jaeger et al., 2014a]). In sum, these sampling biases are difficult to accurately quantify and often affect a difference between coreand log-derived measurements. The velocity curve presented here below the logged interval (i.e., deeper than $288 \mathrm{~m}$ WMSF) likely represents minimum estimates because the apparent average velocity decreases with depth as opposed to a typical compaction trend and also because these measurements were collected on the WRMSL, which tends to be negatively affected by incompletely full core liners (Walczak et al., 2015). These measurements were fitted with one of three splines depending on the availability of data in the depth interval (Fig. F5). In the upper $270 \mathrm{~m}$, we sampled from a spline achieving $R^{2}$ $=0.9287$ and rmse $=0.0454$ compared to the full data compilation. Deeper than $270 \mathrm{~m}$ on the combined CSF-A/WMSF scale, we fit the data using two splines. The more aggressive fit had $R^{2}=0.7774$ and rmse $=0.1020$. Except for data gaps near 270-550 and $700-780 \mathrm{~m}$ on the combined depth scale, where the aggressive fit predicts unusually large variability, we sample from this spline. The spline that we used for interpolation in the poorly constrained intervals reached $R^{2}=0.6698$ and rmse $=0.1165$ with data from the compilation deeper than $\sim 270 \mathrm{~m}$ on the combined depth scale.

Figure F14 summarizes the cross-correlation before and after the tie. The cross-correlation is a statistic commonly used to quantify the similarity of signals based on a lag time or offset. In this case we desire a maximum cross-correlation value between our synthetic and seismic signals near zero lag time close to the site. Before visual matching, the maximum crosscorrelation within five traces of the site, nearest Trace 2622 on Line GOA 2505, was 0.367 with Trace 2619 with a lag of $13 \mathrm{~ms}$ in the 340-1410 ms window. At the site trace, the cross-correlation was calculated as -0.118 at $0 \mathrm{~ms}$ lag. After a bulk shift and visual matching, we calculate that the maximum cross-correlation occurred at Trace 2624 and $3 \mathrm{~ms}$ lag. At Trace 2622, the maximum cross-correlation was calculated to be 0.188 at $0 \mathrm{~ms}$ lag, whereas the maximum cross-correlation for this trace, 0.350 , occurred with $3 \mathrm{~ms}$ lag. To avoid overinterpretation of the data, we made minimal matches and shifts $(n=$ 4) to achieve visually acceptable results between the synthetic and seismic traces (Fig. F15). Although the correlation is low compared to sites with more complete drilling records (e.g., the well to seismic tie in White and Simm [2003] reported an $R^{2}$ of $~ 0.87$ ) the overall character of the seismic and synthetic traces agrees well visually among their major trends and reflectors. High-amplitude reflectors in seismic Line GOA 2505 near 475 and 895 ms TWT are well matched by reflectors in the synthetic seismic at $\sim 390$ and 820 m seismic depth below sea level (SSL). Low core recovery, variable data quality and source, data compilation handling, and a short logged interval relative to the length of the well-to-seismic tie are likely responsible for the low correlation. Figure F15, shown with the final TDR (Table T4), better illustrates the quality of the tie.

The preliminary TDR created shipboard (see Fig. F11 in the "Site U1420" chapter [Jaeger et al., 2014b]) may represent a maximum depth relationship by using linear approximation through WRMSL velocity measurements near 680 and $900 \mathrm{~m}$ CSF-A. We observe that values here are notably higher than the mean of the WRMSL velocity measurements overall but are low compared to the expected in situ logging trend. Unlike a typical compaction trend that increases with depth, the apparent average velocity decreases with depth at this site. Only a single WRMSL density measurement above the logged interval was available, and this measurement value is low among the data set, which results in the calculation of a smaller than expected reflection coefficient 
at the seafloor. We directly used bulk density values from the WRMSL, which are likely minimum values compared to ideal recovery with perfectly full core liners or an equivalently wireline logged section measured in situ (see the "Site U1420" chapter [Jaeger et al., 2014b]). Although this effect may be particularly important below the end of the logged interval (i.e., below $288 \mathrm{~m} \mathrm{WMSF}$ ), the variability of the core-derived measurements provides changes in the synthetic trace which we correlate to events in the seismic traces near the well location.

\section{Site U1421}

At Site U1421, we derived a bulk density compilation used for data fitting and interpolation from STMSL and WRMSL measurements from Holes U1421AU1421C on the CCSF-B scale. We fitted two splines to the data and selectively sampled from them to create a continuous record. Using the more aggressive fit, we achieved $R^{2}=0.9309$ and rmse $=0.0599$ with the compilation moving average for the full interval (Fig. F6). Although we found that it was possible to achieve higher $R^{2}$ values, the fit presented here is the best fit constrained such that no density $<1 \mathrm{~g} /$ $\mathrm{cm}^{3}$ was predicted. At $\sim 150-220$, near 410 , and 500$575 \mathrm{~m}$ CCSF-B, we sampled a smoother spline fit with $R^{2}=0.6980$ and rmse $=0.1404$.

The full velocity compilation used for spline fitting was created by compiling the logged measurements with the core compilation measurements. In the upper $92 \mathrm{~m}$, we sampled the spline-fitted data from the core compilation with $R^{2}=0.7908$ and $\mathrm{rmse}=$ 0.0674. The bottom interval consisted of the fitted log-derived compilation from a spline with $R^{2}=$ 0.9718 and rmse $=0.03833$. Although both $\log$ and core data were available for a short interval, in the area of overlap we sampled from the spline fitted to the wireline-logged data.

We made matches between the synthetic and seismic traces, which were minimal in number $(n=14)$ and scale. Before matching, the maximum cross-correlation within five traces of the site, nearest Trace 411 on Line GOA 2503, was 0.417 with Trace 414 at -1 ms lag when correlating the 980-1650 ms window. At the site trace we calculate the cross-correlation with the synthetic at $0 \mathrm{~ms}$ lag to be 0.365 , which was also the maximum in the trace window at any lag. After matching, the maximum cross-correlation, 0.500 , occurred at Trace 413 with $0 \mathrm{~ms}$ lag. At Trace 411 , the nearest to the site, the zero-lag cross-correlation was 0.413 and the trace maximum cross-correlation, 0.448, occurred at $1 \mathrm{~ms}$ lag (Fig. F16). Again, despite the low correlation compared to ties based on more complete data, we find that the character of the seismic and synthetic traces agrees well visually in overlay (Fig. F15). High-amplitude reflectors on seismic Line GOA 2503 near 1279, and $1620 \mathrm{~ms}$ TWT match well with the synthetic at 1020 and $1395 \mathrm{~m}$ SSL. The final TDR is shown in Table T1 with reference to both the SSL and meters seismic depth below seafloor (SSF) datums. Additionally, we note the high agreement between our final TDR and the check shot time-depth constraints, which suggests a well-calibrated model.

\section{Application to previous work}

We apply the TDR to estimate depths of several reflectors in seismic Lines GOA 2503 and GOA 2505. These sections and horizons are discussed and interpreted in Worthington et al. (2010) and the "Site U1420" and "Site U1421" chapters (Jaeger et al., $2014 b, 2014 c)$. Here, we simply provide a summary table of the depths of these horizons as calculated by our TDR (Fig. F17). At Site U1420, we were able to provide depth estimates for Horizons H1A, H1B, H1, H2A, H2B, H2C, H2D, and H2, which had TWTs less than $\sim 1550 \mathrm{~ms}$. At Site U1421 we provided depth estimates for Horizons H1B, H1, and H2A. For each location we estimated the TWT from the appropriate seismic section near the well and interpolated from our final TDR to generate depth estimates.

\section{Acknowledgments}

All data used in this report were collected aboard the R/V JOIDES Resolution during Integrated Ocean Drilling Program Expedition 341, June-August 2013. We thank the shipboard science party, captain, and crew for making this work possible and Dr. Gail Christeson for helpful discussion. This research was partially funded by a postexpedition award to L. Worthington and a UNM-EPS Murdoch Fellowship to W. Clary.

\section{References}

Berger, A.L., Gulick, S.P.S., Spotila, J.A., Upton, P., Jaeger, J.M., Chapman, J.B., Worthington, L.A., Pavlis, T.L., Ridgway, K.D., Willems, B.A., and McAleer, R.J., 2008. Quaternary tectonic response to intensified glacial erosion in an orogenic wedge. Nature Geoscience, 1:793799. http://dx.doi.org/10.1038/ngeo334

Daigle, H., and Piña, O.L., 2016. Data report: permeability, consolidation properties, and grain size of sediments from Sites U1420 and U1421, offshore southern Alaska. In Jaeger, J.M., Gulick, S.P.S., LeVay, L.J., and the Expedition 341 Scientists, Proceedings of the Integrated Ocean Drilling Program, 341: College Station, TX (Integrated Ocean Drilling Program). http://dx.doi.org/10.2204/ iodp.proc.341.201.2016 
Jaeger, J.M., Gulick, S.P.S., LeVay, L.J., Asahi, H., Bahlburg, H., Belanger, C.L., Berbel, G.B.B., Childress, L.B., Cowan, E.A., Drab, L., Forwick, M., Fukumura, A., Ge, S., Gupta, S.M., Kioka, A., Konno, S., März, C.E., Matsuzaki, K.M., McClymont, E.L., Mix, A.C., Moy, C.M., Müller, J., Nakamura, A., Ojima, T., Ridgway, K.D., Rodrigues Ribeiro, F., Romero, O.E., Slagle, A.L., Stoner, J.S., St-Onge, G., Suto, I., Walczak, M.H., and Worthington, L.L., 2014a. Methods. In Jaeger, J.M., Gulick, S.P.S., LeVay, L.J., and the Expedition 341 Scientists, Proceedings of the Integrated Ocean Drilling Program, 341: College Station, TX (Integrated Ocean Drilling Program). http:/ /dx.doi.org/10.2204/iodp.proc.341.102.2014

Jaeger, J.M., Gulick, S.P.S., LeVay, L.J., Asahi, H., Bahlburg, H., Belanger, C.L., Berbel, G.B.B., Childress, L.B., Cowan, E.A., Drab, L., Forwick, M., Fukumura, A., Ge, S., Gupta, S.M., Kioka, A., Konno, S., März, C.E., Matsuzaki, K.M., McClymont, E.L., Mix, A.C., Moy, C.M., Müller, J., Nakamura, A., Ojima, T., Ridgway, K.D., Rodrigues Ribeiro, F., Romero, O.E., Slagle, A.L., Stoner, J.S., St-Onge, G., Suto, I., Walczak, M.H., and Worthington, L.L., 2014b. Site U1420. In Jaeger, J.M., Gulick, S.P.S., LeVay, L.J., and the Expedition 341 Scientists, Proceedings of the Integrated Ocean Drilling Program, 341: College Station, TX (Integrated Ocean Drilling Program). http://dx.doi.org/10.2204/iodp.proc.341.106.2014

Jaeger, J.M., Gulick, S.P.S., LeVay, L.J., Asahi, H., Bahlburg, H., Belanger, C.L., Berbel, G.B.B., Childress, L.B., Cowan, E.A., Drab, L., Forwick, M., Fukumura, A., Ge, S., Gupta, S.M., Kioka, A., Konno, S., März, C.E., Matsuzaki, K.M., McClymont, E.L., Mix, A.C., Moy, C.M., Müller, J., Nakamura, A., Ojima, T., Ridgway, K.D., Rodrigues Ribeiro, F., Romero, O.E., Slagle, A.L., Stoner, J.S., St-Onge, G., Suto, I., Walczak, M.H., and Worthington, L.L., 2014c. Site U1421. In Jaeger, J.M., Gulick, S.P.S., LeVay, L.J., and the Expedition 341 Scientists, Proceedings of the Integrated Ocean Drilling Program, 341: College Station, TX (Integrated Ocean Drilling Program). http://dx.doi.org/10.2204/iodp.proc.341.107.2014

Koehler, R.D., Farrell, R.-E., Burns, P.A.C., and Combellick, R.A., 2012. Quaternary faults and folds in Alaska: a digi- tal database. Alaska Division of Geological \& Geophysical Surveys Miscellaneous Publication, 141. http://doi.org/ $10.14509 / 23944$

Manley, W., and Kaufman, D.S., 2002. Alaska Paleoglacier Atlas: Boulder, CO (Institute of Arctic and Alpine Research, University of Colorado). http://instaar.colorado.edu/QGISL/ak_paleoglacier_atlas/

Silverman, B.W., 1985. Some aspects of the spline smoothing approach to nonparametric regression curve fitting. Journal of the Royal Statistical Society, Series B (Methodological), 47(1):1-52. http://www.jstor.org/stable/2345542

Walczak, M.H., Mix, A.C., Willse, T., Slagle, A., Stoner, J.S., Jaeger, J., Gulick, S., LeVay, L., Kioka, A., and the IODP Expedition 341 Scientific Party, 2015. Correction of non-intrusive drill core physical properties data for variability in recovered sediment volume. Geophysical Journal International, 202(2):1317-1323. http://dx.doi.org/ 10.1093/gji/ggv204

Worthington, L.L, Gulick, S.P.S., and Pavlis, T.L., 2010. Coupled stratigraphic and structural evolution of a glaciated orogenic wedge, offshore St. Elias orogen, Alaska. Tectonics, 29:TC6013-TC6039. http://dx.doi.org/ 10.1029/2010TC002723

White, R., 1997. The accuracy of well ties: practical procedures and examples. SEG Technical Program Expanded Abstracts, 1997(RC1):816-819. https://doi.org/ 10.1190/1.1886137

White, R.E., 1980. Partial coherence matching of synthetic seismograms with seismic traces. Geophysical Prospecting, 28(3):333-358. https://doi.org/10.1111/j.13652478.1980.tb01230.x

White, R.E., and Simm, R., 2003. Tutorial: good practice in well ties. First Break, 21(10):75-83.

Initial receipt: 31 August 2016

Acceptance: 15 April 2017

Publication: 28 June 2017

MS 341-204 
Figure F1. Site U1419-U1421 locations (white circles). Satellite imagery (Source: esri) is draped over topography and bathymetry (Source: NGA, USGS). Red lines = major quaternary faults (Koehler et al., 2012), BT = blind thrust faults (after Worthington et al., 2010). Medium blue = maximum glacial extent during the last $\sim 3 \mathrm{My}$, light blue = Wisconsin Last Glacial Maximum extent (Manley and Kaufman, 2002). Dashed yellow lines = approximate locations of seismic Lines GOA 2502, GOA 2503, and GOA 2505 from seismic Survey EW0408 collected aboard the R/V Maurice Ewing in 2004.

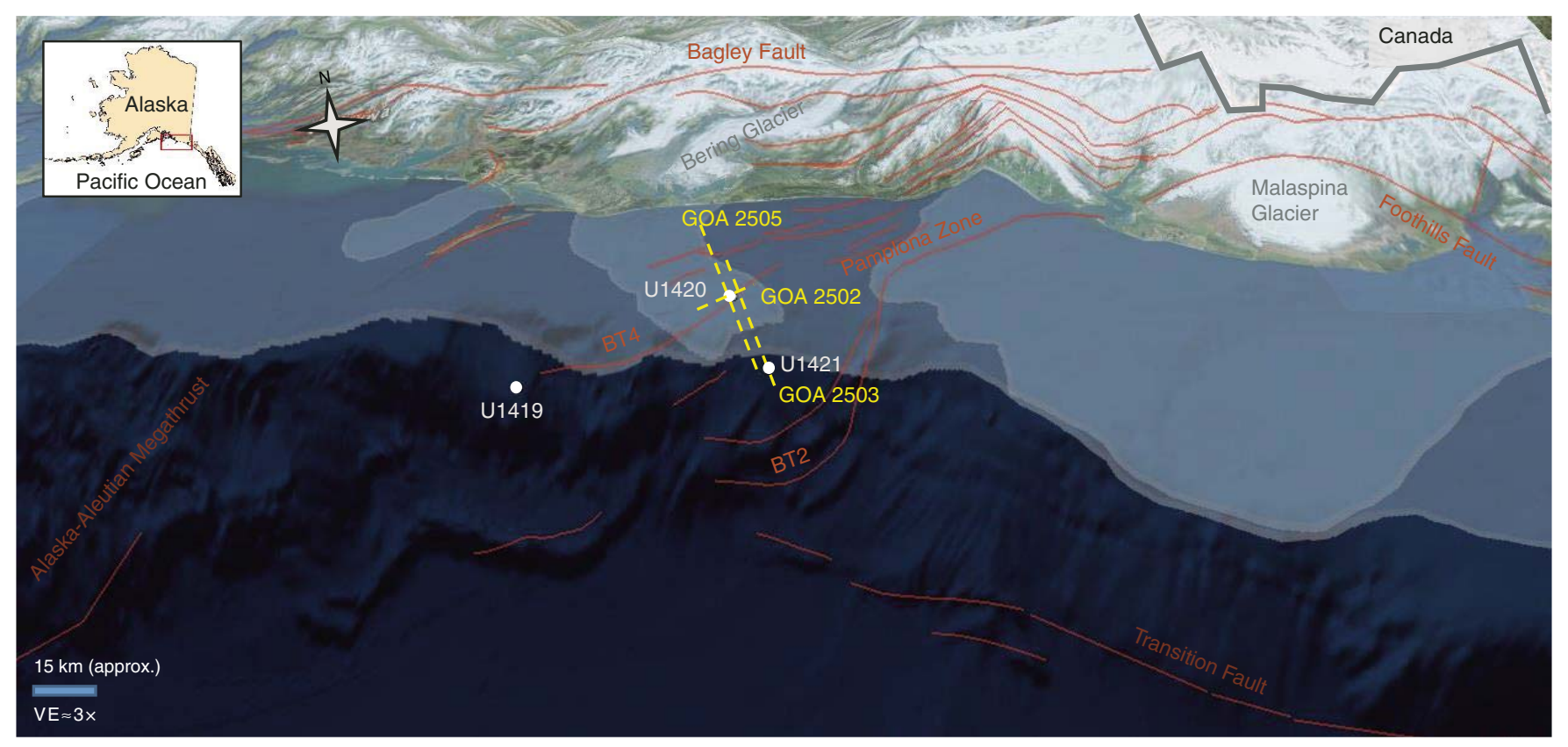


Figure F2. Schematic of general handling and relevant physical property analyses of cores collected during Expedition 341. Core handling and data collection are described in greater detail in the "Site U1420" and "Site U1421" chapters (Jaeger et al., 2014b, 2014c).

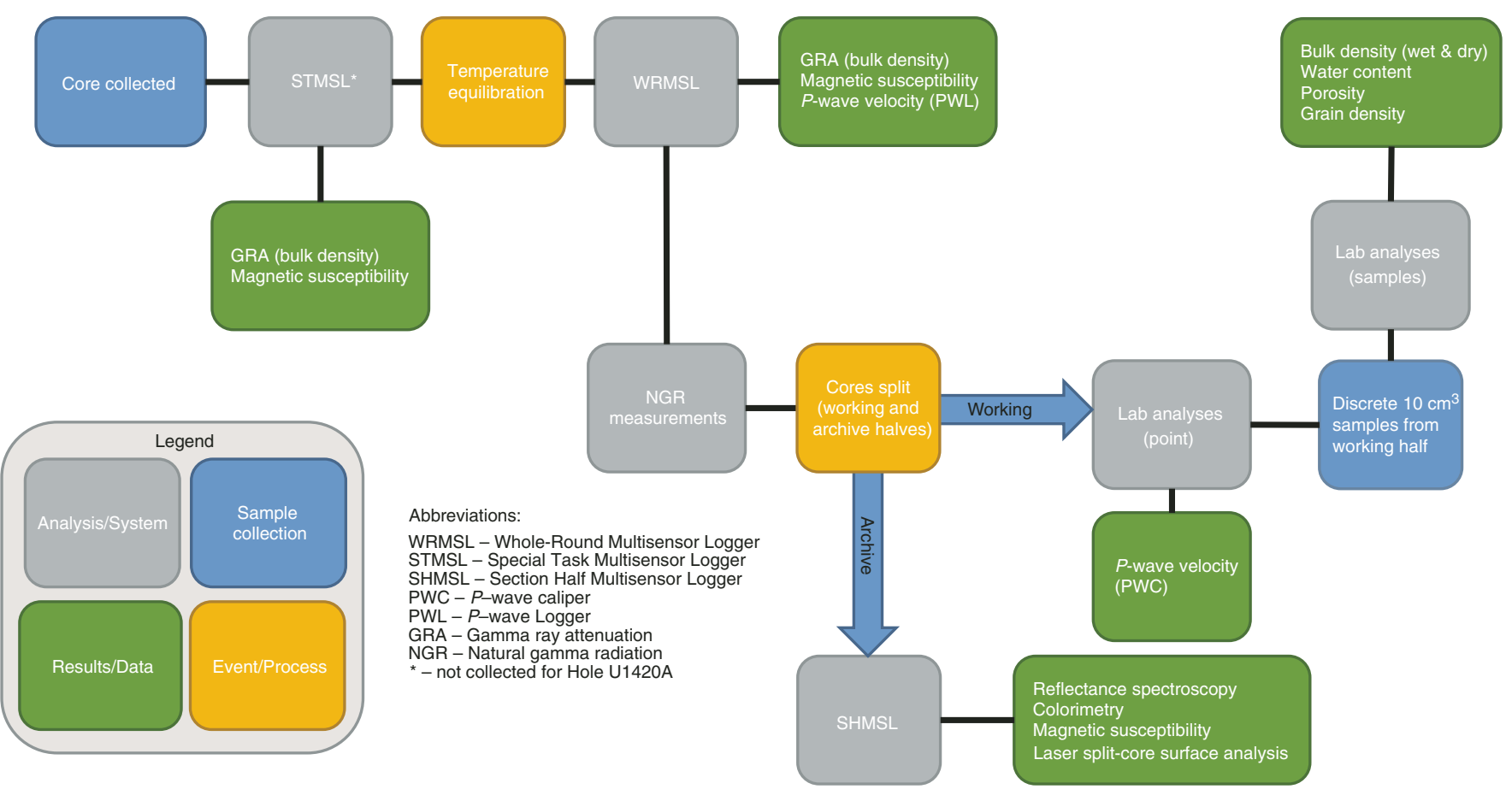


Figure F3. Summary of logs recorded by the sonic-induction tool string. Phasor dual induction-spherically focused resistivity: $\mathrm{IDPH}=$ deep induction, $\mathrm{IMPH}=$ medium induction, $\mathrm{SFLU}=$ shallow spherically focused resistivity. A. Hole U1420A. B. Hole U1421A. (From the Site U1421 chapter [Jaeger et al., 2014c].)
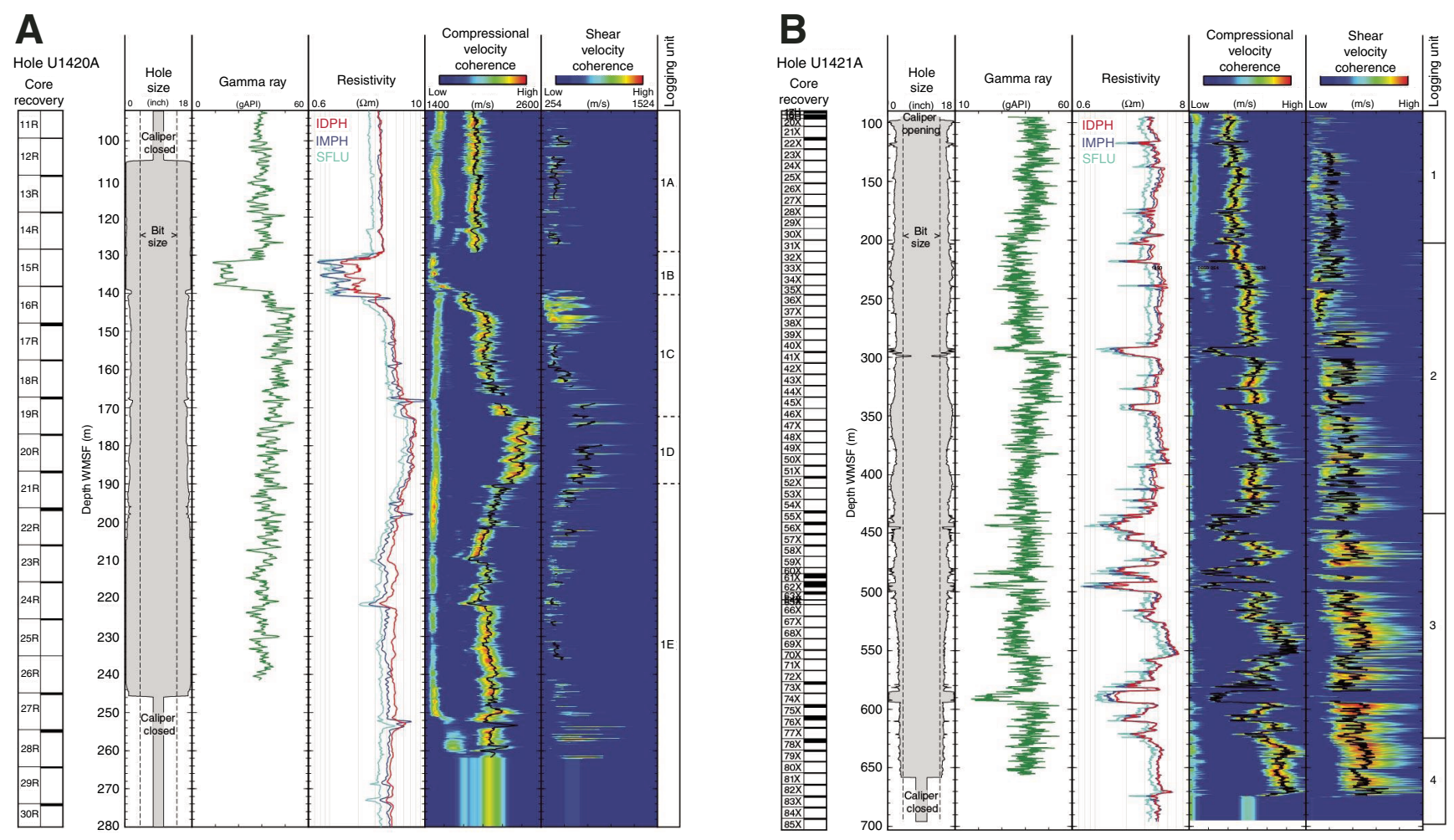
Figure F4. A. Compressional wave velocity measurements from core-compiled and log-compiled sources, Site U1421. B. Detail of interval showing overlap of core and log measurements before and after shifting the core measurements by $53 \mathrm{~m} / \mathrm{s}$ to match the average of logging data. C. Compiled $V_{\mathrm{p}}$ measurements used for fitting.
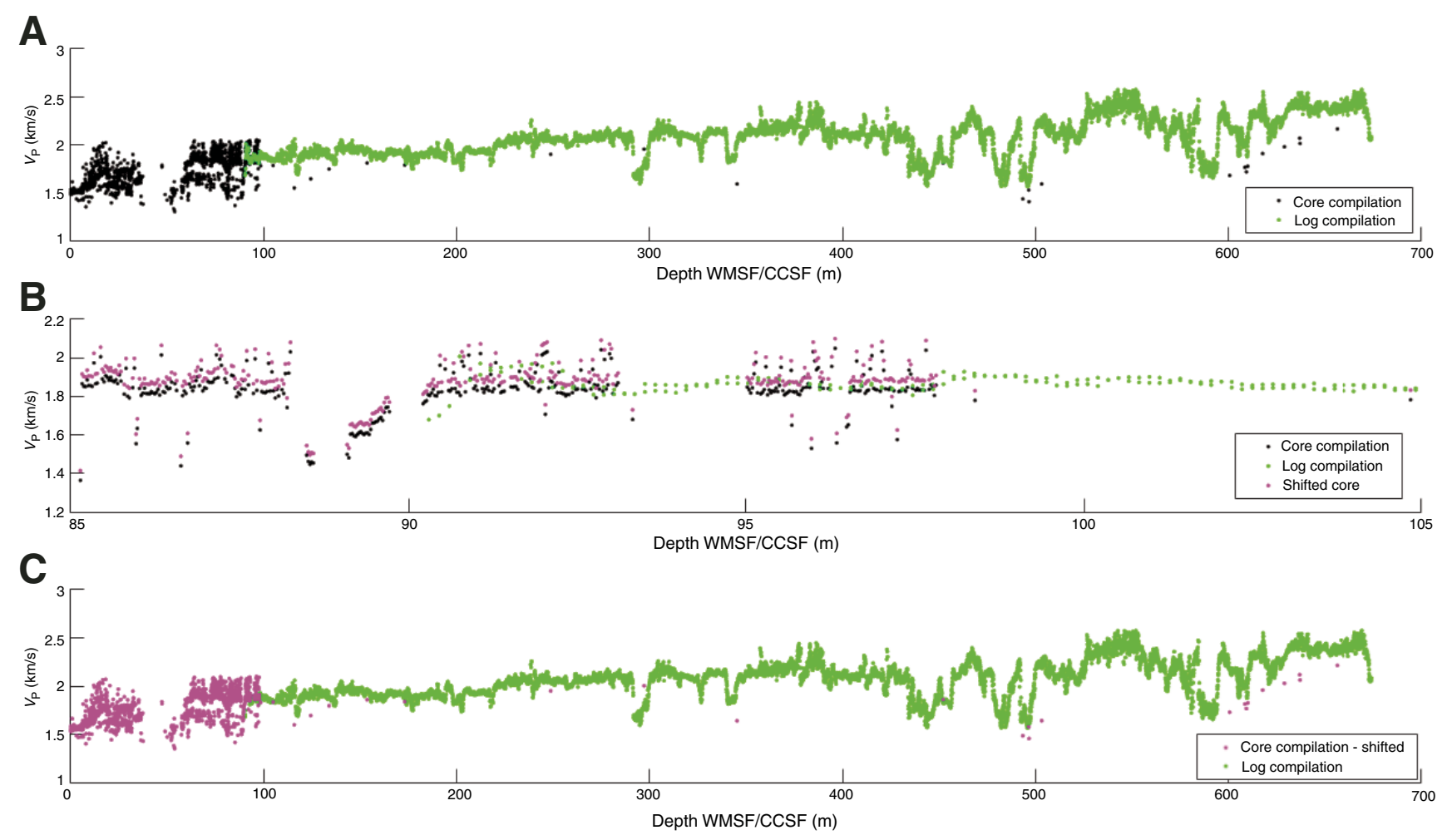
Figure F5. Bulk density compilation and fits, Site U1420. Goodness of fit characteristics for multiple spline fits derived by comparison with the moving 19-sample average. Goodness of fit characteristics are reported for respective intervals on the figure. sse $=$ sum of squared errors, $r m s e=$ root mean squared error.

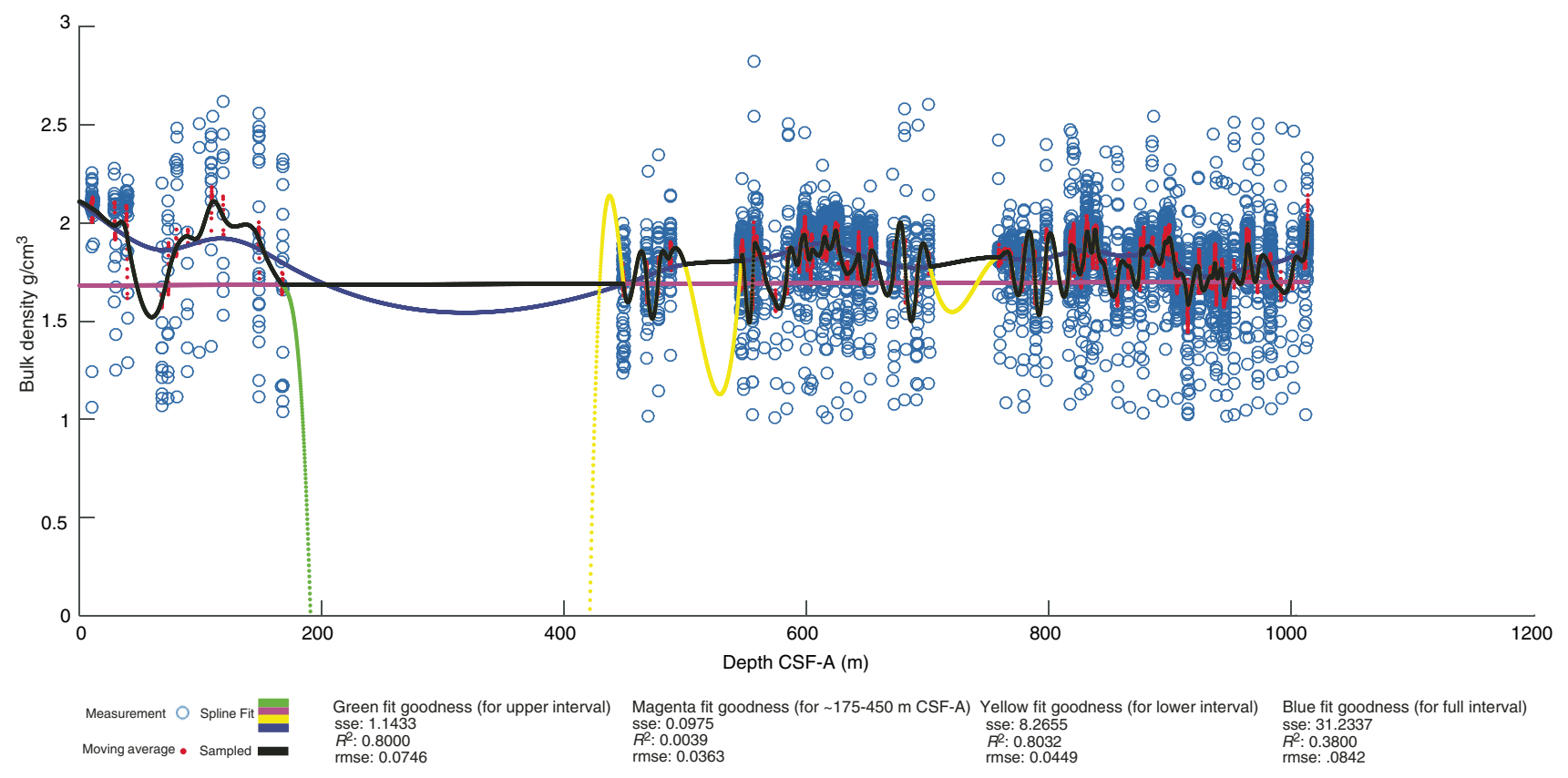


Figure F6. Compressional wave velocity measurements compilation and spline fits, Site U1420. The final sampled curve is at a rate of $0.1524 \mathrm{~m}$. Goodness of fit characteristics are reported in the figure for data included in the compilation within respective intervals. In the upper interval, $\sim 270 \mathrm{~m}$, the yellow aggressively fitted curve was sampled. Deeper than $270 \mathrm{~m}$ on the combined depth scale, we sampled either the smoothed cyan curve for the poorly constrained intervals or the magenta curve, which we fitted aggressively for comparatively well constrained intervals. sse $=$ sum of squared errors, $r m s e=$ root mean squared error.

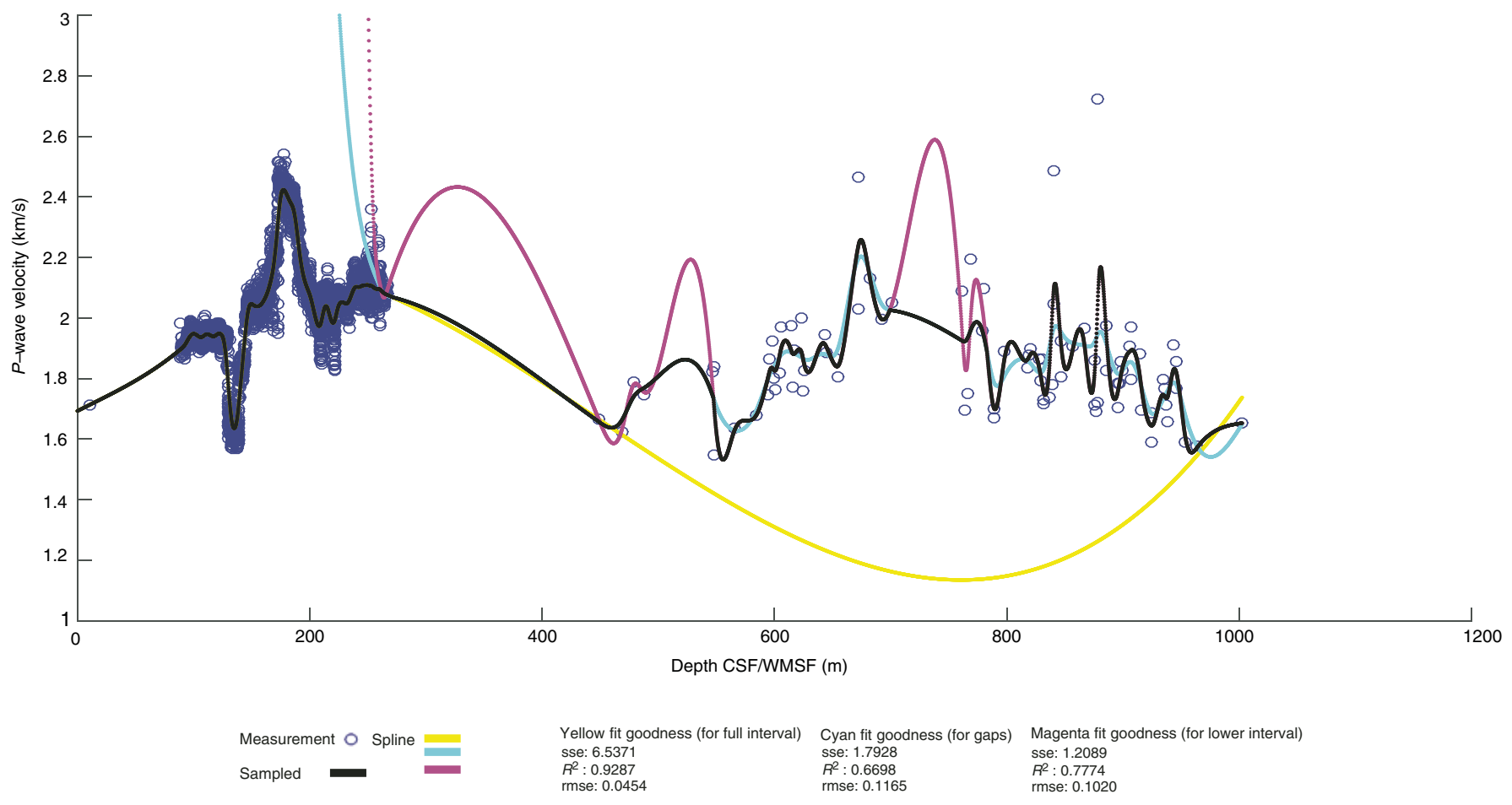


Figure F7. Bulk density compilation and fits, Site U1421. The final curve (black) was sampled at a rate of 0.1524 $\mathrm{m}$. We selected the green fit for the compilation because it had the highest $R^{2}$ value such that the minimum density prediction was $1 \mathrm{~g} / \mathrm{cm}^{3}$. For intervals near 180-220, 400-420, and 500-580 m CCSF-B, we sampled a spline fitted more conservatively for the whole data set (magenta). Measurements shown before outlier removal.

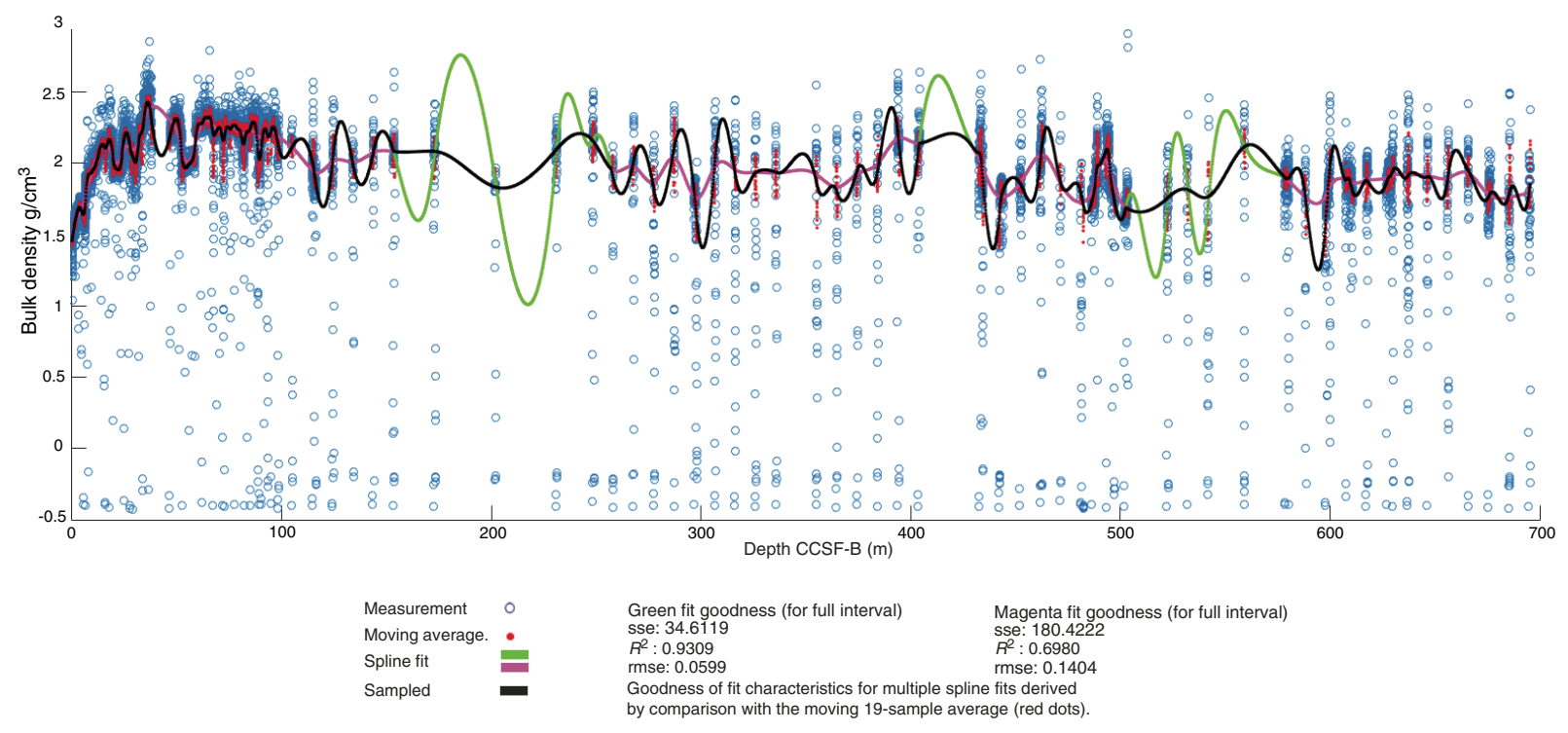


Figure F8. A. Compressional wave velocity data compilation, Site U1421. Core data and in situ logging measurements were fitted independently with two splines. B. Detail of the overlapping interval shows intersection point of the core-fitted and log-fitted splines selected to splice the curves together such that use of the logging data was prioritized. C. Final sampled curve for the full interval with core data and logging data.

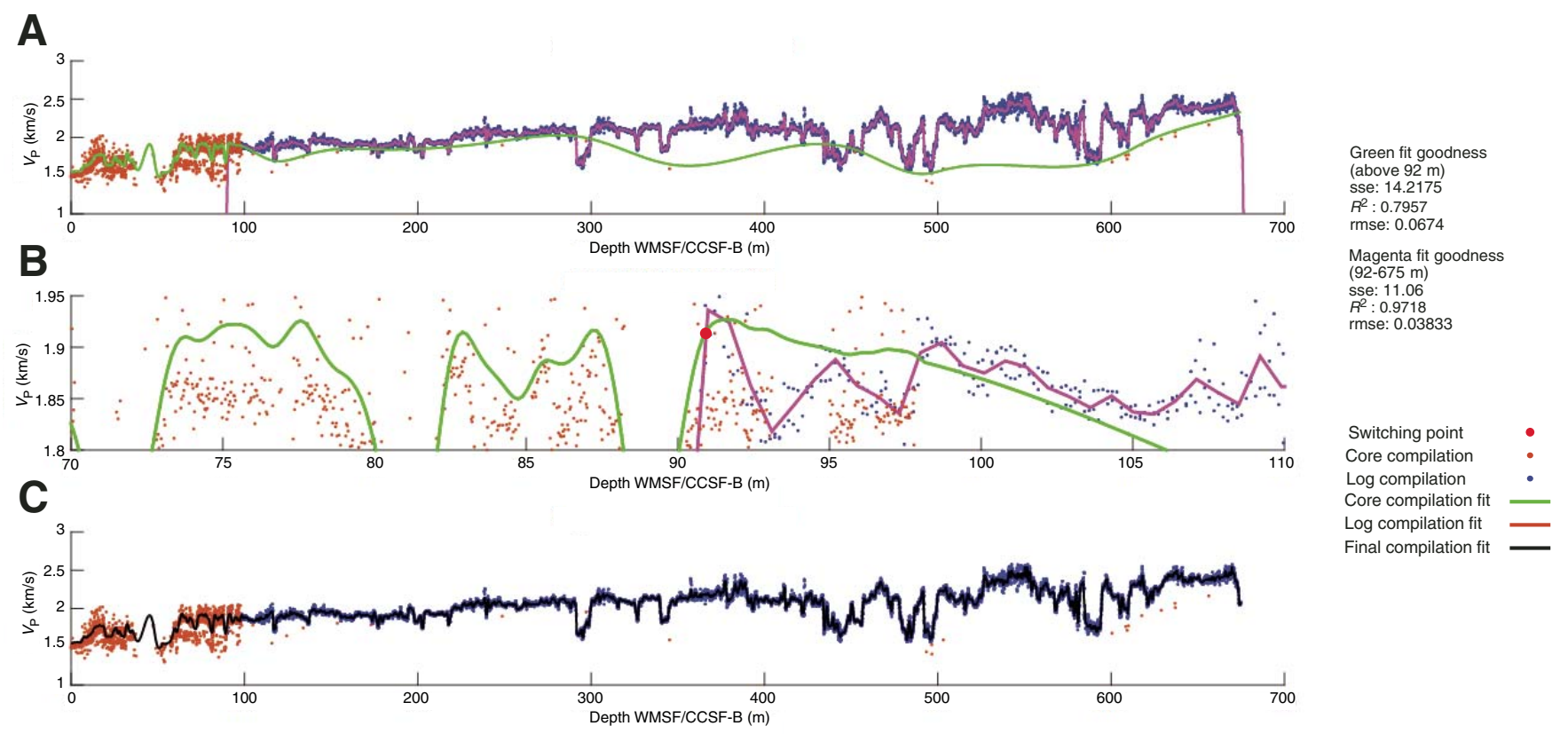


Figure F9. A. Original bulk density WRMSL data set and fit for Site U1420 shown with interpolated physical property curve sampled at $0.1524 \mathrm{~m}$ spacing. B. Compressional wave velocity compilation from sonic log and PWC core-derived measurements, Site U1420. Interpolated physical property curve sampled at $0.1524 \mathrm{~m}$ interval and fitted as described in the text. C. Original bulk density WRMSL and STMSL data set compilation and fit for Hole U1421A shown with interpolated physical property curve sampled at $0.1524 \mathrm{~m}$ spacing. D. Compressional wave velocity compilation from sonic log and PWC core-derived measurements, Hole U1421A. Interpolated physical property curve sampled at $0.1524 \mathrm{~m}$ interval and fitted as described in the text.
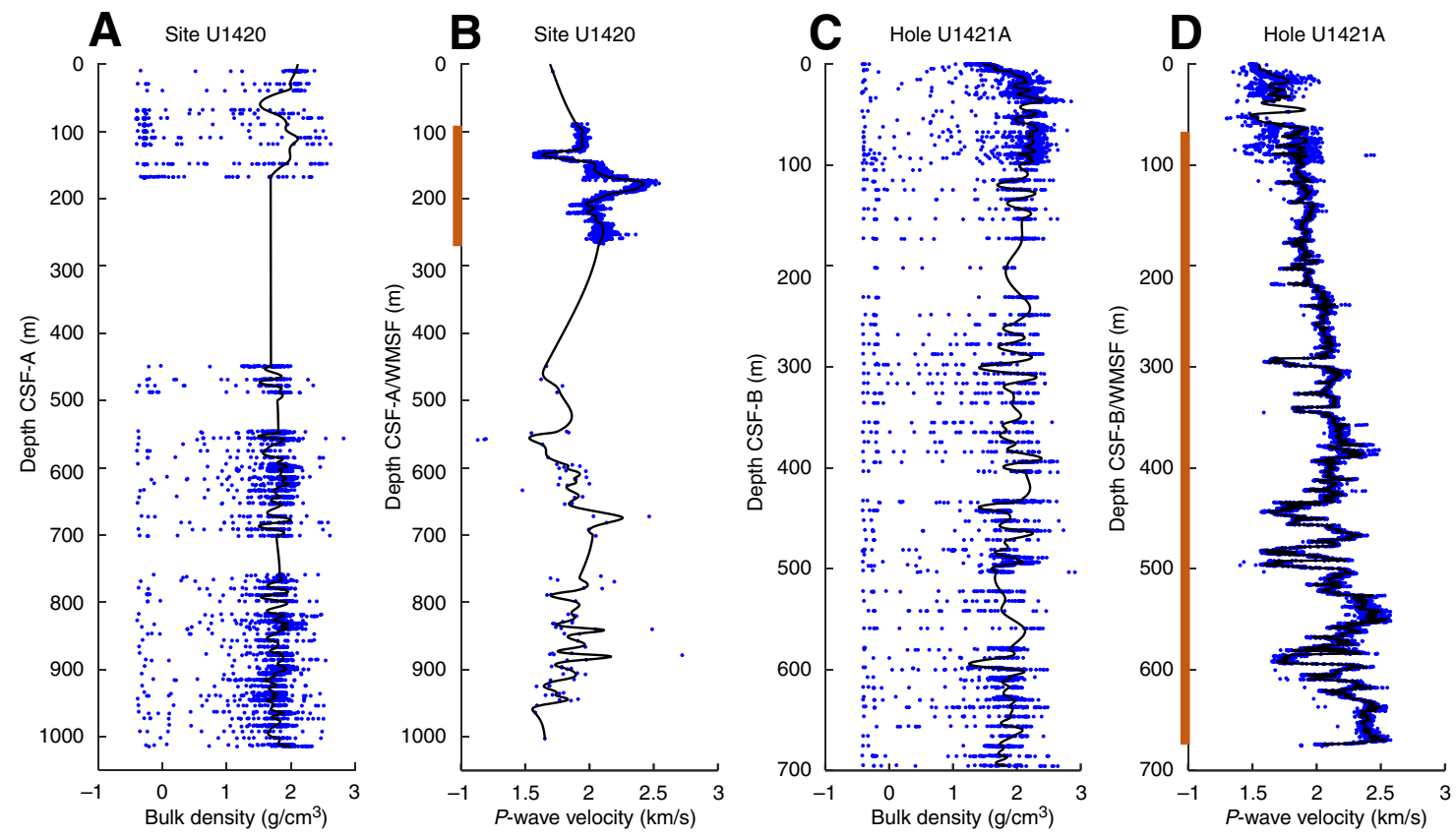
Figure F10. A. Initial interval velocity from the sonic compressional wave velocity data, Site U1420. First panel shows drift value for calibrating. Second panel shows the interval velocity from the constructed velocity curve, and third panel shows the results of calibration. The primary role of calibration in this instance is to initially match the seafloor between the velocity curve and interval velocity model and to create a $5 \mathrm{~m}$ sampling interval for the interval velocity. Note also that the upper interval to the seafloor is a constant velocity in the output interval velocity. TWT $=$ two-way traveltime. B. First panel shows drift curve for sonic and VSP calibration for Site U1421. Second panel shows interval velocity from VSP check shots and seafloor constraints. Third panel shows the interval velocity for the original sonic log and the calibrated sonic log after adjusting with the drift value. The seismic depth scale below sea level (SSL) is derived from the TDR by using the logging seafloor depth and combined WMSF/CCSF/CSF scales.
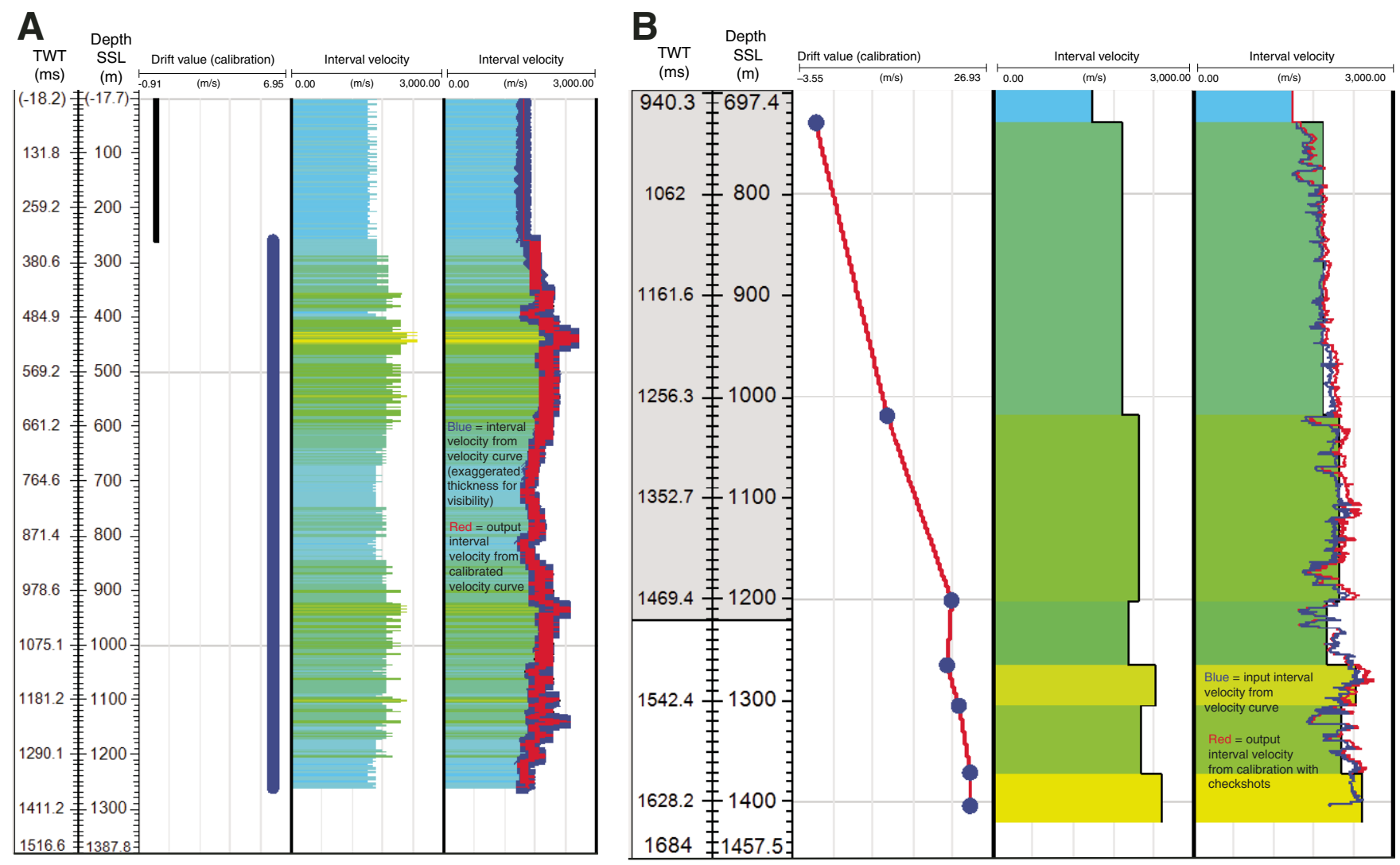
Figure F11. A. Spectral properties of initial Ricker wavelet used at each site. The Ricker wavelet was centered at $0 \mathrm{~ms}$ with $128 \mathrm{~ms}$ length. B. Spectral properties of extracted wavelet used at Site U1420 according to the Roy White method. C. Spectral properties of extracted wavelet used at Site U1421 according to the Roy White method.

A

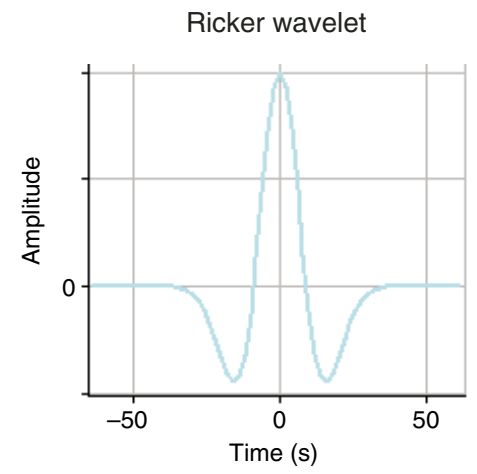

B

Extracted wavelet GOA 2503
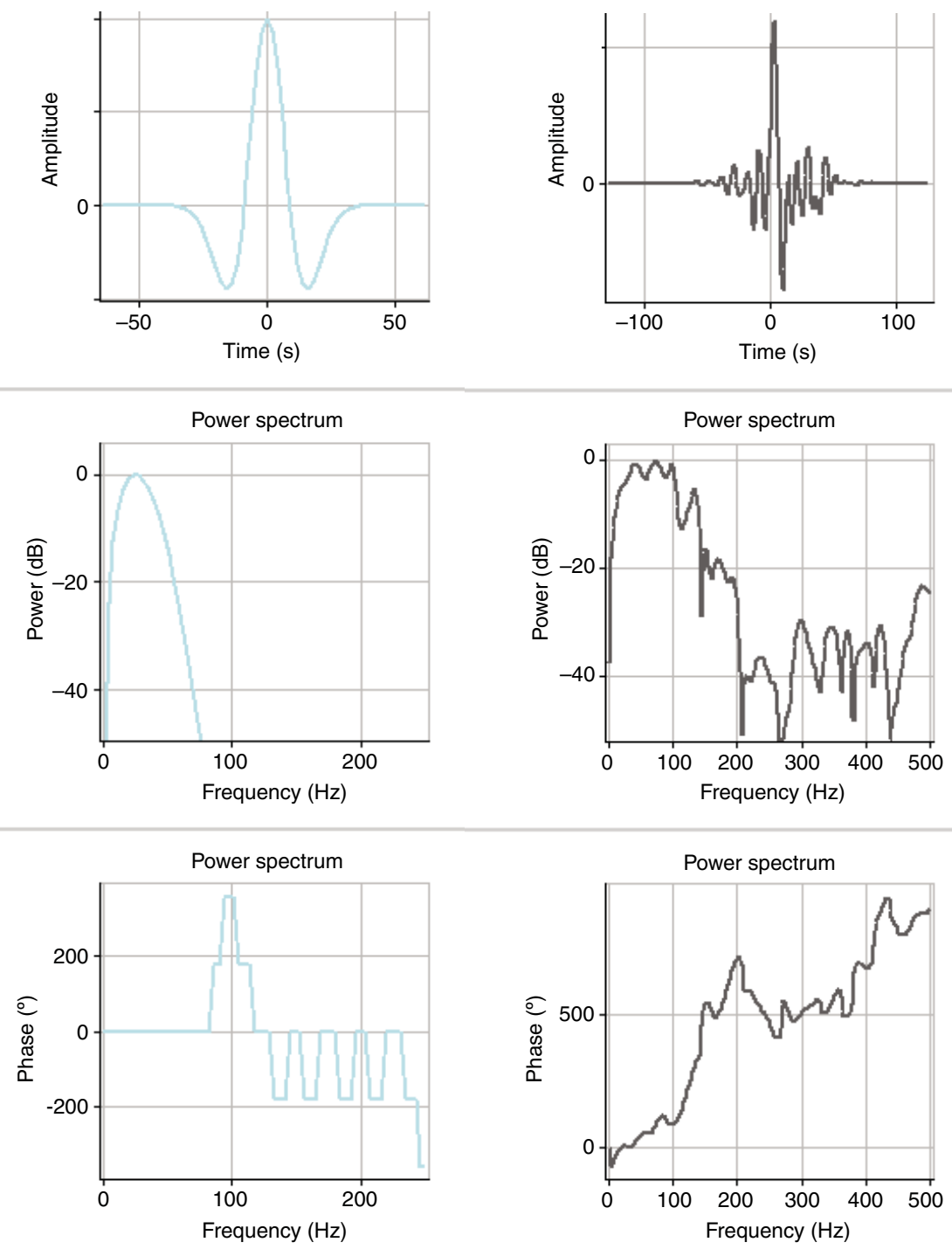

C

Extracted wavelet GOA 2505
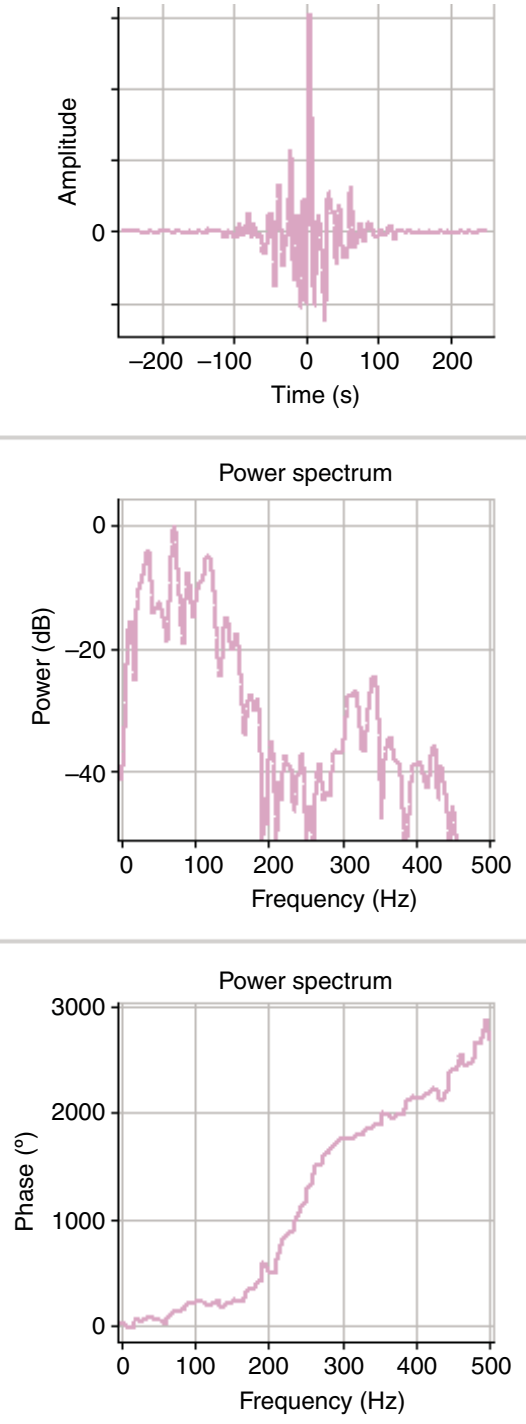
Figure F12. A. Traces from USGS 2004 EW0408 survey seismic Line GOA 2505 shown at shot locations 26172627 with initial TDR and visual matches (green) between the seismic and synthetic generated at Site U1420. The last two panels show the calculated interval velocity and reflectivity. Synthetic seismic was produced using the reflectivity series and the extracted wavelet shown in Figure F11C. TWT = two-way traveltime. B. Synthetic shown with seismic traces 2617-2627 and the TDR after applying the matches. The two right panels show the calculated interval velocity and reflectivity.

A

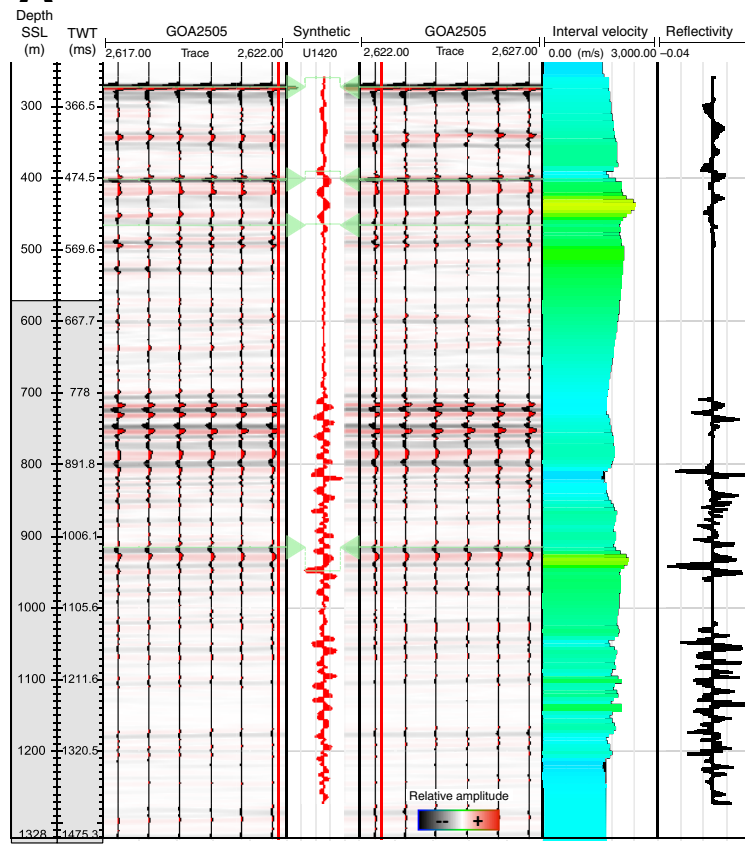

B

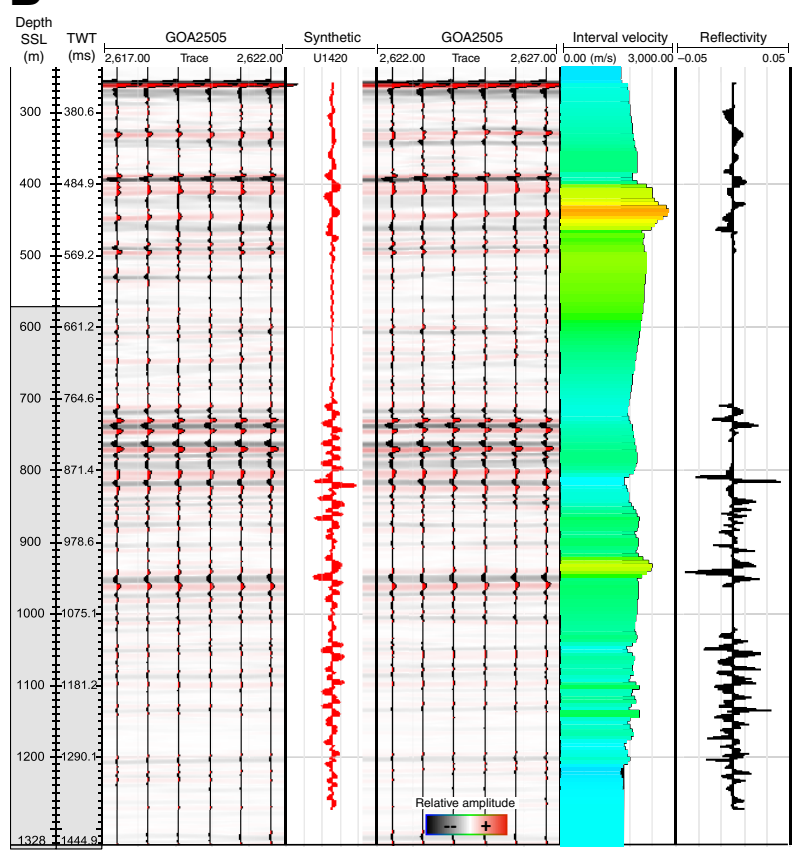


Figure F13. A. Traces from 2004 EW0408 survey seismic Line GOA 2503 shown at shot locations 406-416 with initial TDR and visual matches (green) between the seismic and synthetic. The last two panels show the calculated interval velocity and reflectivity. Synthetic seismic was produced using the reflectivity series and the extracted wavelet shown in Figure F11B. TWT = two-way traveltime. B. Synthetic shown with seismic traces 406416 and the TDR after applying the matches. The two right panels show the calculated interval velocity and reflectivity.
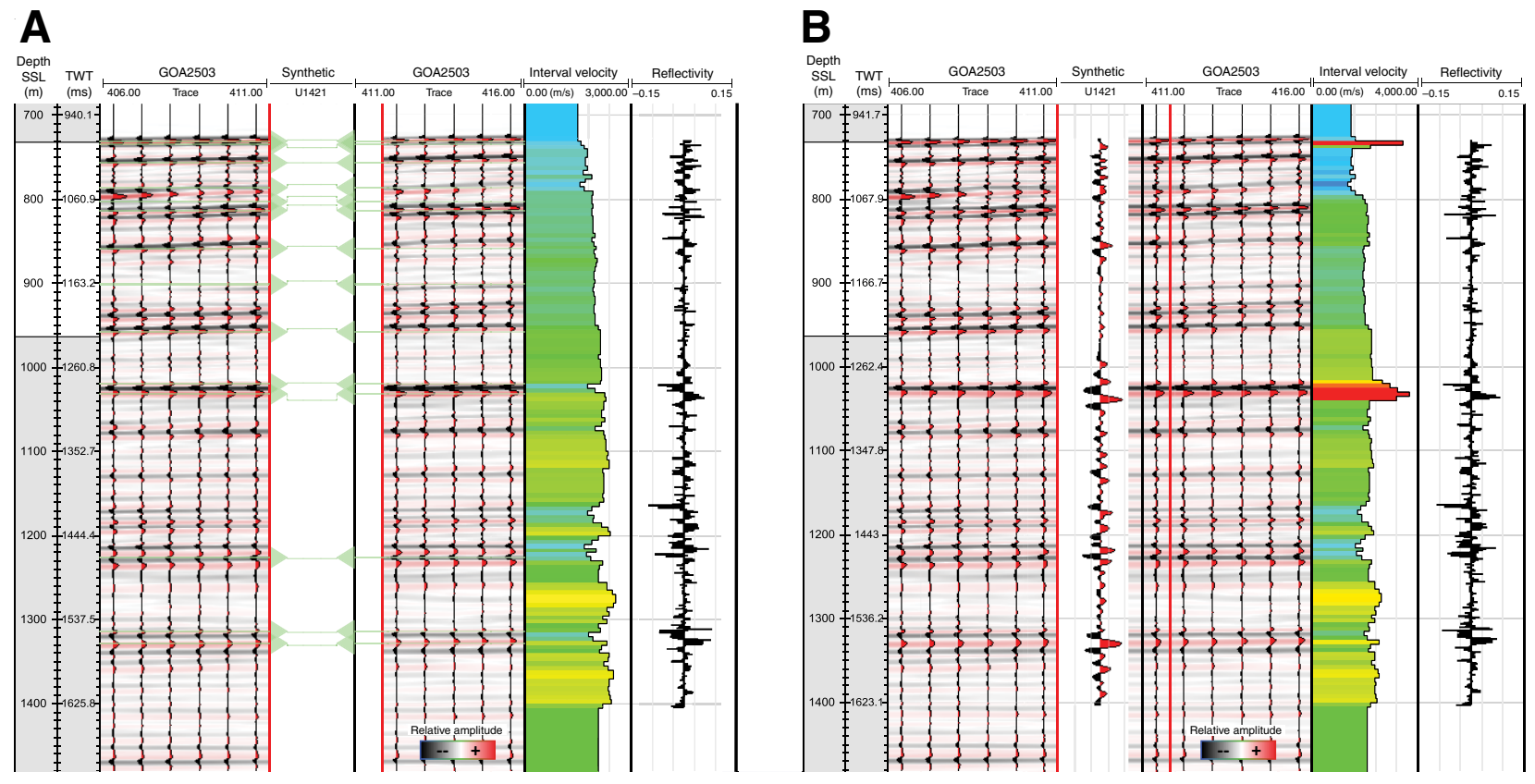
Figure F14. Cross-correlation before (left) and after (right) the tie, Site U1420. Before matching, the maximum cross-correlation within 5 traces of the site, nearest Trace 2622 on Line GOA 2505, was 0.367 with Trace 2619 with a lag of $13 \mathrm{~ms}$ in the $340-1410 \mathrm{~ms}$ window. At the site trace, the cross-correlation was calculated as -0.118 at $0 \mathrm{~ms}$ lag. After a bulk shift and matching, we calculate that the maximum cross-correlation occurred at Trace 2624 and $3 \mathrm{~ms}$ lag. At Trace 2622, the maximum cross-correlation was calculated to be 0.188 at $0 \mathrm{~ms}$ lag, whereas the maximum cross-correlation for this trace, 0.350 , occurs with $3 \mathrm{~ms}$ lag. White asterisk $=$ trace of maximum cross-correlation.

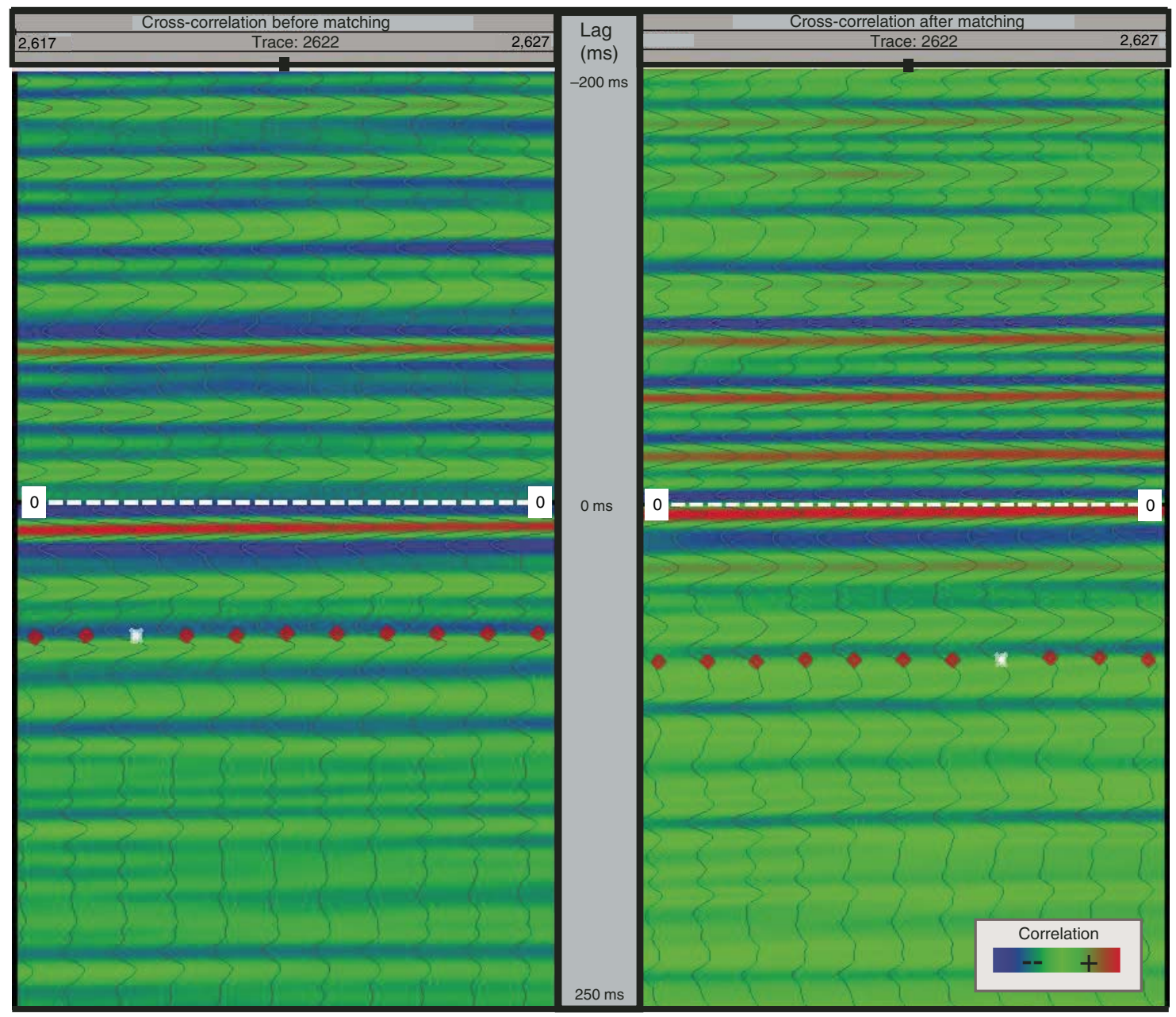


Figure F15. A. Synthetic seismic overlain for Site U1420 shown on seismic Line GOA 2505 near the site location with the final TDR. TWT = two-way traveltime. B. Synthetic seismic overlain for Site U1421 shown on Line GOA 2503 near the site location with the final TDR.

A

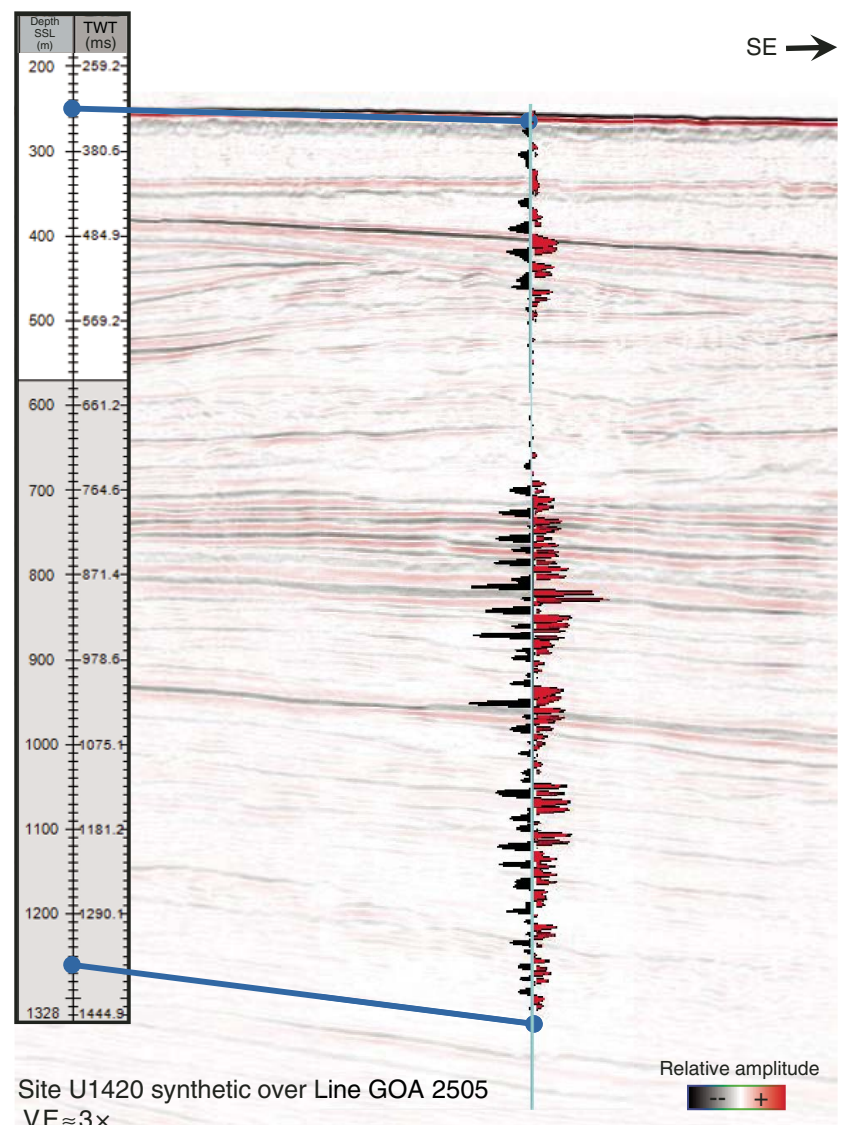

B

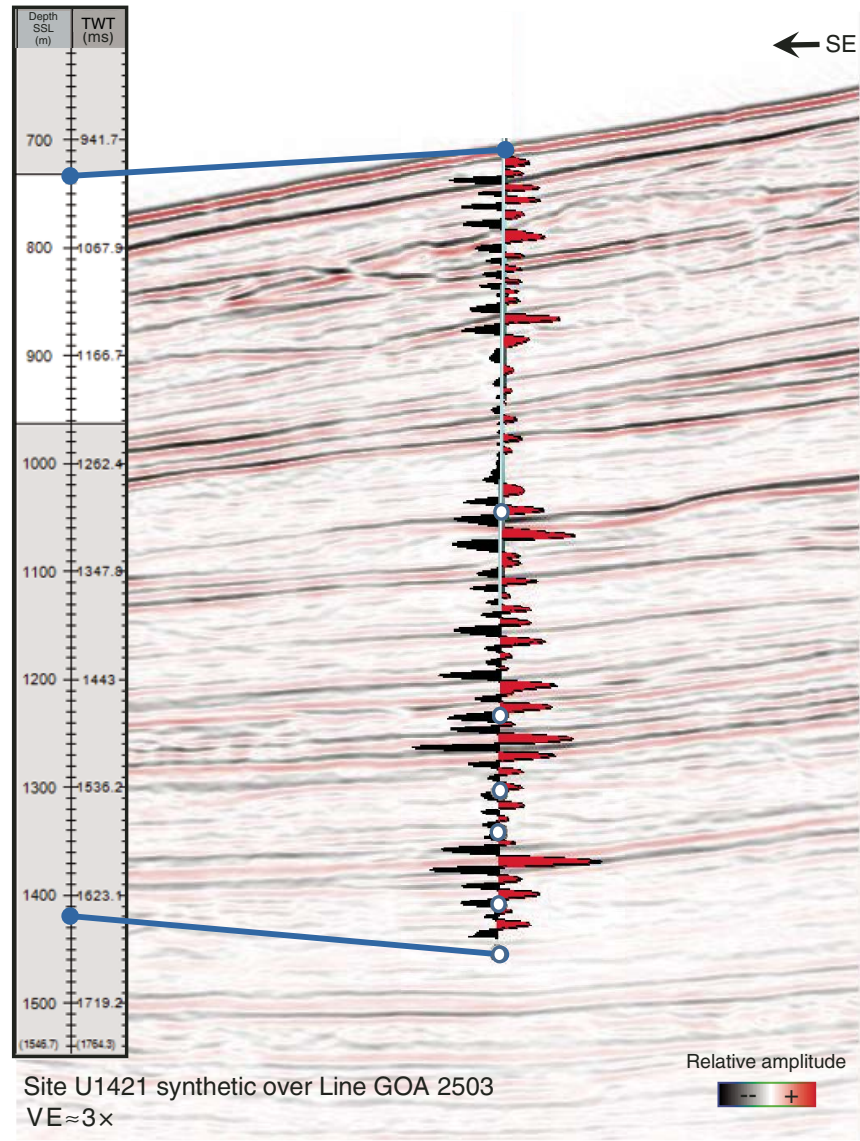

O Checkshot 
Figure F16. Cross-correlation results for the tie, Site U1421. Before matching (left), the maximum cross-correlation within 5 traces of the site, nearest Trace 411 on Line GOA 2503, was 0.417 with Trace 414 at $-1 \mathrm{~ms} \mathrm{lag}$ when correlating the 980-1650 ms window. At the site trace, we calculate the cross-correlation with the synthetic at $0 \mathrm{~ms}$ lag to be 0.365 , which was also the maximum cross-correlation value in the trace window at any lag. After matching (right), the maximum cross-correlation, 0.500 , occurred at Trace 413 with $0 \mathrm{~ms}$ lag. At Trace 411 , the nearest to the site, the zero lag cross-correlation was 0.413 and the trace maximum cross-correlation, 0.448 , occurred at $1 \mathrm{~ms}$ lag. White asterisk = trace of maximum cross-correlation.

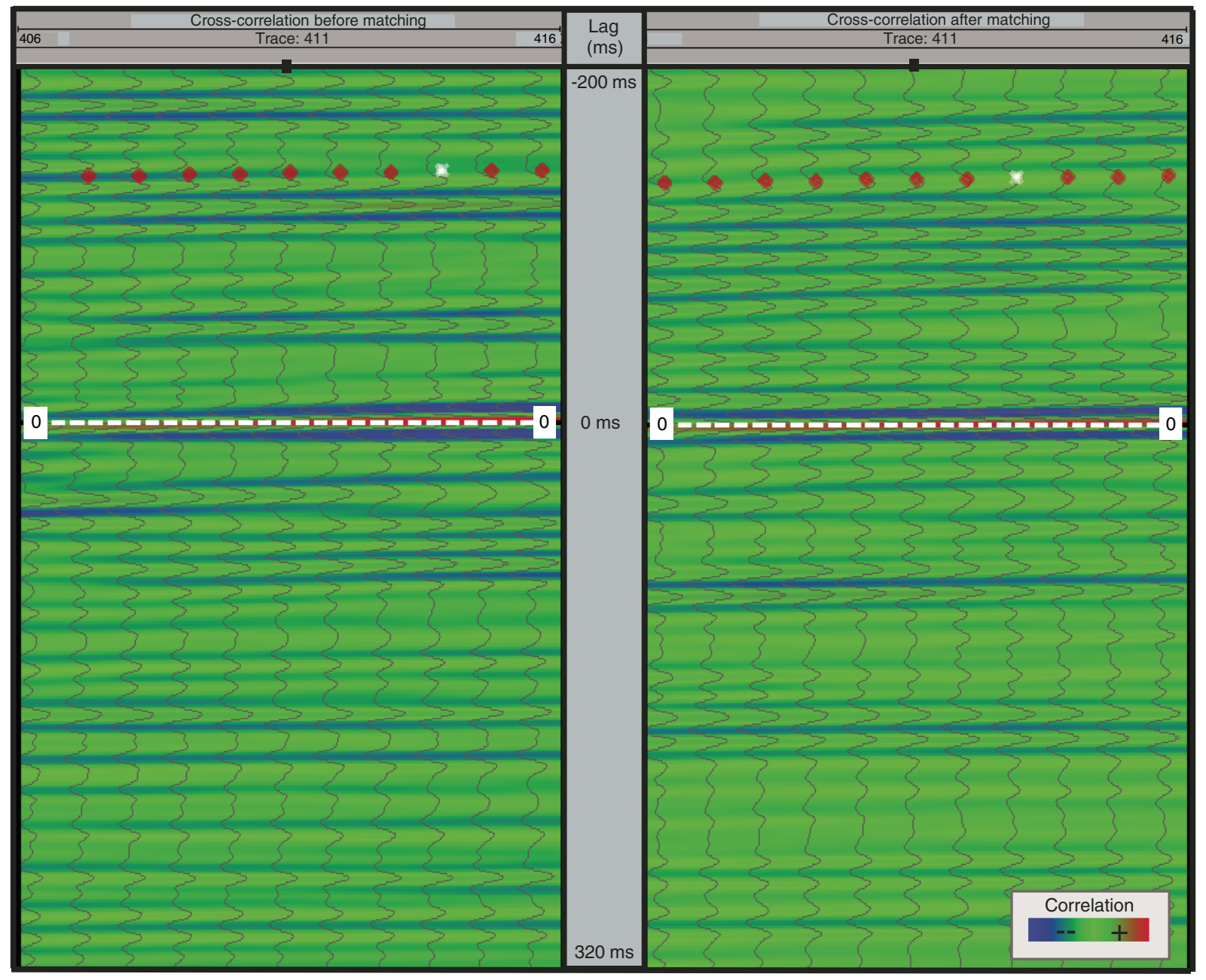


Figure F17. Horizons penetrated by drilling at (A) Site U1420 (see Fig. F30 in the Site U1420 chapter [Jaeger et al., 2014b]) and (B) Site U1421 (see Fig. F38 in the Site U1421 chapter [Jaeger et al., 2014c]) with depths interpreted using the final TDR created in this study. In each case we estimated horizon two-way traveltimes (TWTs) from seismic Lines GOA 2505 and GOA 2503, as appropriate, after the interpretations of Worthington et al. (2010) and Berger et al. (2008). Depth estimates are provided in both meters below seafloor in the seismic depth scale below seafloor (SSF) and meters seismic depth below sea level (SSL) references developed from each TDR.

A

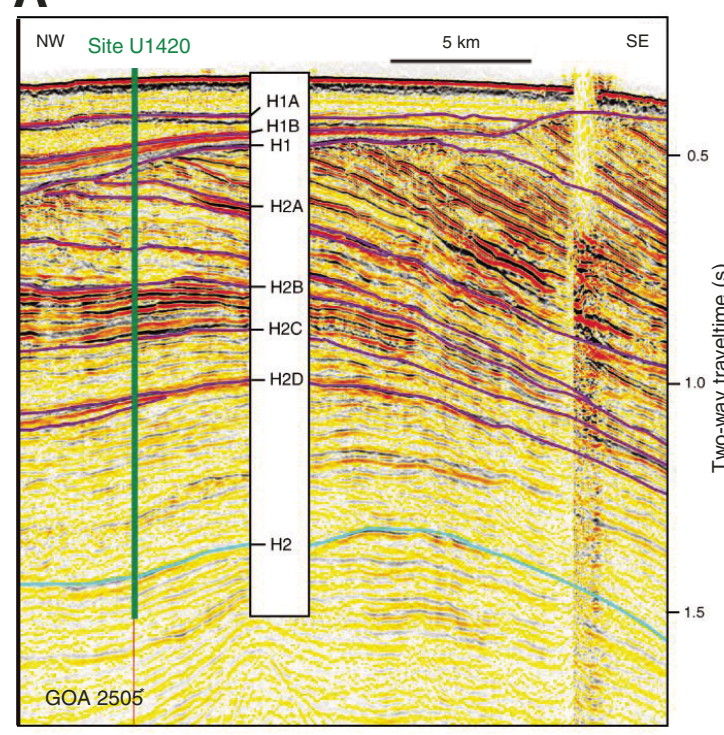

\begin{tabular}{|c|c||c||c|}
\hline Horizon & TWT $(\mathrm{ms})$ & SSF $(\mathrm{m})$ & SSL $(\mathrm{m})$ \\
\hline H1A & 414 & 72 & 331 \\
\hline H1B & 470 & 127 & 386 \\
\hline H1 & 516 & 180 & 439 \\
\hline H2A & 564 & 236 & 495 \\
\hline H2B & 773 & 450 & 709 \\
\hline H2C & 903 & 568 & 827 \\
\hline H2D & 1016 & 681 & 940 \\
\hline H2 & 1422 & 1049 & 1308 \\
\hline
\end{tabular}

B

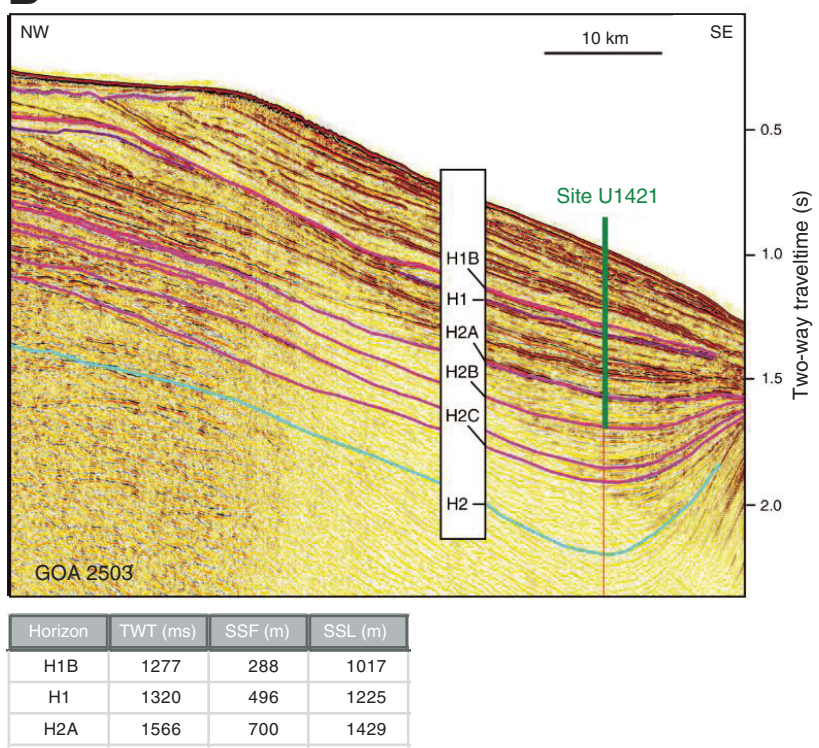

*Seismic Profiles GOA2503 and GOA2505 acquired in

2004 aboard the R/V Maurice

Ewing as part of a pre survey

cruise for Expedition 341. 
Table T1. Time-depth relationship of final tie, Site U1421.

\begin{tabular}{|c|c|c|c|c|c|c|c|c|}
\hline $\begin{array}{l}\text { TWT } \\
\text { (ms) }\end{array}$ & $\begin{array}{c}\text { Depth } \\
\text { SSL } \\
(\mathrm{m})\end{array}$ & $\begin{array}{c}\text { Depth } \\
\text { SSF } \\
\text { (m) }\end{array}$ & $\begin{array}{l}\text { TWT } \\
\text { (ms) }\end{array}$ & $\begin{array}{l}\text { Depth } \\
\text { SSL } \\
\text { (m) }\end{array}$ & $\begin{array}{l}\text { Depth } \\
\text { SSF } \\
(\mathrm{m})\end{array}$ & $\begin{array}{l}\text { TWT } \\
\text { (ms) }\end{array}$ & $\begin{array}{l}\text { Depth } \\
\text { SSL } \\
(\mathrm{m})\end{array}$ & $\begin{array}{l}\text { Depth } \\
\text { SSF } \\
(\mathrm{m})\end{array}$ \\
\hline 981.5 & 730 & 1 & 1235.47 & 970 & 241 & 1453.43 & 1210 & 481 \\
\hline 984.42 & 735 & 6 & 1239.95 & 975 & 246 & 1459.62 & 1215 & 486 \\
\hline 988.98 & 740 & 11 & 1244.42 & 980 & 251 & 1464.78 & 1220 & 491 \\
\hline 995.58 & 745 & 16 & 1248.9 & 985 & 256 & 1470.69 & 1225 & 496 \\
\hline 1002.19 & 750 & 21 & 1253.47 & 990 & 261 & 1476.05 & 1230 & 501 \\
\hline 1009.03 & 755 & 26 & 1257.94 & 995 & 266 & 1480.53 & 1235 & 506 \\
\hline 1015.8 & 760 & 31 & 1262.4 & 1000 & 271 & 1485.2 & 1240 & 511 \\
\hline 1022.32 & 765 & 36 & 1266.81 & 1005 & 276 & 1489.94 & 1245 & 516 \\
\hline 1029.31 & 770 & 41 & 1271.2 & 1010 & 281 & 1494.65 & 1250 & 521 \\
\hline 1035.44 & 775 & 46 & 1275.57 & 1015 & 286 & 1499.36 & 1255 & 526 \\
\hline 1042.28 & 780 & 51 & 1279.34 & 1020 & 291 & 1503.62 & 1260 & 531 \\
\hline 1049.69 & 785 & 56 & 1282.76 & 1025 & 296 & 1507.85 & 1265 & 536 \\
\hline 1056.59 & 790 & 61 & 1285.86 & 1030 & 301 & 1511.8 & 1270 & 541 \\
\hline 1062.7 & 795 & 66 & 1288.57 & 1035 & 306 & 1515.63 & 1275 & 546 \\
\hline 1067.91 & 800 & 71 & 1291.71 & 1040 & 311 & 1519.44 & 1280 & 551 \\
\hline 1072.87 & 805 & 76 & 1296.36 & 1045 & 316 & 1523.36 & 1285 & 556 \\
\hline 1077.67 & 810 & 81 & 1301.02 & 1050 & 321 & 1527.59 & 1290 & 561 \\
\hline 1082.5 & 815 & 86 & 1305.78 & 1055 & 326 & 1531.73 & 1295 & 566 \\
\hline 1087.38 & 820 & 91 & 1310.58 & 1060 & 331 & 1536.17 & 1300 & 571 \\
\hline 1092.12 & 825 & 96 & 1315.15 & 1065 & 336 & 1540.41 & 1305 & 576 \\
\hline 1096.85 & 830 & 101 & 1319.9 & 1070 & 341 & 1545.12 & 1310 & 581 \\
\hline 1101.65 & 835 & 106 & 1325.1 & 1075 & 346 & 1549.71 & 1315 & 586 \\
\hline 1106.41 & 840 & 111 & 1329.77 & 1080 & 351 & 1554.85 & 1320 & 591 \\
\hline 1111.05 & 845 & 116 & 1334.35 & 1085 & 356 & 1559.66 & 1325 & 596 \\
\hline 1115.89 & 850 & 121 & 1338.84 & 1090 & 361 & 1563.61 & 1330 & 601 \\
\hline 1120.55 & 855 & 126 & 1343.35 & 1095 & 366 & 1568.19 & 1335 & 606 \\
\hline 1125.64 & 860 & 131 & 1347.85 & 1100 & 371 & 1572.94 & 1340 & 611 \\
\hline 1130.87 & 865 & 136 & 1352.27 & 1105 & 376 & 1577.15 & 1345 & 616 \\
\hline 1135.98 & 870 & 141 & 1356.74 & 1110 & 381 & 1581.4 & 1350 & 621 \\
\hline 1141.01 & 875 & 146 & 1361.1 & 1115 & 386 & 1585.87 & 1355 & 626 \\
\hline 1146.06 & 880 & 151 & 1365.42 & 1120 & 391 & 1590.11 & 1360 & 631 \\
\hline 1151.17 & 885 & 156 & 1370.1 & 1125 & 396 & 1594.12 & 1365 & 636 \\
\hline 1156.39 & 890 & 161 & 1374.74 & 1130 & 401 & 1598.08 & 1370 & 641 \\
\hline 1161.59 & 895 & 166 & 1379.4 & 1135 & 406 & 1602.28 & 1375 & 646 \\
\hline 1166.67 & 900 & 171 & 1384.04 & 1140 & 411 & 1606.46 & 1380 & 651 \\
\hline 1171.74 & 905 & 176 & 1388.68 & 1145 & 416 & 1610.68 & 1385 & 656 \\
\hline 1176.96 & 910 & 181 & 1393.3 & 1150 & 421 & 1614.87 & 1390 & 661 \\
\hline 1182.03 & 915 & 186 & 1398.04 & 1155 & 426 & 1619.01 & 1395 & 666 \\
\hline 1187.03 & 920 & 191 & 1402.66 & 1160 & 431 & 1623.08 & 1400 & 671 \\
\hline 1192.05 & 925 & 196 & 1407.61 & 1165 & 436 & 1627.62 & 1405 & 676 \\
\hline 1197.16 & 930 & 201 & 1413.05 & 1170 & 441 & 1632.44 & 1410 & 681 \\
\hline 1202.28 & 935 & 206 & 1418.87 & 1175 & 446 & 1637.26 & 1415 & 686 \\
\hline 1207.29 & 940 & 211 & 1424.18 & 1180 & 451 & 1642.09 & 1420 & 691 \\
\hline 1212.28 & 945 & 216 & 1429.54 & 1185 & 456 & 1646.91 & 1425 & 696 \\
\hline 1217.33 & 950 & 221 & 1434.29 & 1190 & 461 & & & \\
\hline 1222.05 & 955 & 226 & 1438.72 & 1195 & 466 & & & \\
\hline 1226.53 & 960 & 231 & 1443 & 1200 & 471 & & & \\
\hline 1230.99 & 965 & 236 & 1447.96 & 1205 & 476 & & & \\
\hline
\end{tabular}

TWT = two-way traveltime, SSL = seismic depth below sea level, SSF = seismic depth below seafloor. Bold text = data near check shots. 
Table T2. Site U1420 and U1421 data summary including location and physical properties measurement availability.

\begin{tabular}{|c|c|c|c|c|c|c|c|c|c|c|c|c|c|c|c|c|}
\hline Hole & Latitude & Longitude & $\begin{array}{l}\text { Depth } \\
\text { (mbrf) }\end{array}$ & $\begin{array}{l}\text { Cores } \\
(N)\end{array}$ & $\begin{array}{c}\text { Interval } \\
\text { cored } \\
\text { (m) }\end{array}$ & $\begin{array}{l}\text { Interval } \\
\text { recovered } \\
(\mathrm{m})\end{array}$ & $\begin{array}{l}\text { Recovery } \\
\text { (\%) }\end{array}$ & $\begin{array}{l}\text { Total } \\
\text { pene- } \\
\text { tration } \\
(\mathrm{m})\end{array}$ & $\begin{array}{l}\text { Total } \\
\text { depth } \\
\text { (mbrf) }\end{array}$ & VSP & $\begin{array}{l}\text { Logged } \\
\text { velocity } \\
\text { (sonic) }\end{array}$ & $\begin{array}{c}\text { PWC } \\
\text { velocity }\end{array}$ & $\begin{array}{c}\text { PWL } \\
\text { velocity }\end{array}$ & $\begin{array}{c}\text { Logged } \\
\text { GRA } \\
\text { density }\end{array}$ & $\begin{array}{l}\text { STMSL } \\
\text { bulk } \\
\text { density }\end{array}$ & WRMSL \\
\hline U1420A & $59^{\circ} 41.3399^{\prime} \mathrm{N}$ & $143^{\circ} 12.0599^{\prime} \mathrm{W}$ & $\begin{array}{c}259.4 \\
\text { Totals: }\end{array}$ & $\frac{106}{106}$ & $\frac{1020.8}{1020.8}$ & $\frac{139.91}{139.91}$ & $\begin{array}{l}13.7 \\
13.7\end{array}$ & $\frac{1020.8}{1020.8}$ & 1280.2 & No & Yes & Yes & No & No & No & Yes \\
\hline U1421A & $59^{\circ} 30.4399^{\prime} \mathrm{N}$ & $143^{\circ} 2.7395^{\prime} \mathrm{W}$ & 729.7 & 85 & 702.7 & 140.72 & 20.0 & 702.7 & 1432.4 & Yes & Yes & Yes & Yes & No & Yes & Yes \\
\hline U1421B & $59^{\circ} 30.4284^{\prime} \mathrm{N}$ & $143^{\circ} 2.7188^{\prime} \mathrm{W}$ & 733.9 & 1 & 6.2 & 6.23 & 100.5 & 6.2 & 740.1 & No & No & No & Yes & No & Yes & Yes \\
\hline U1421C & $59^{\circ} 30.4298^{\prime} \mathrm{N}$ & $143^{\circ} 2.7387^{\prime} \mathrm{W}$ & $\begin{array}{l}733.0 \\
\text { Totals: }\end{array}$ & $\begin{array}{r}6 \\
92\end{array}$ & $\begin{array}{r}38.2 \\
747.1\end{array}$ & $\begin{array}{r}29.06 \\
176.01\end{array}$ & $\frac{76.1}{23.6}$ & $\begin{array}{r}38.2 \\
747.1\end{array}$ & 771.2 & No & No & No & Yes & No & Yes & Yes \\
\hline
\end{tabular}

$\mathrm{VSP}=$ vertical seismic profile, $\mathrm{PWC}=P$-wave caliper, $\mathrm{PWL}=P$-wave logger, $\mathrm{GRA}=$ gamma ray attenuation, $\mathrm{STMSL}=\mathrm{Special}$ Task Multisensor Logger, WRMSL = Whole-Round Multisensor Logger.

Table T3. Check shot data, Site U1421.

\begin{tabular}{ccc}
\hline $\begin{array}{c}\text { Receiver depth } \\
\text { SSL }(\mathrm{m})\end{array}$ & $\begin{array}{c}\text { Receiver depth } \\
\text { SSF }(\mathrm{m})\end{array}$ & $\begin{array}{c}\text { Corrected TWT } \\
(\mathrm{s})\end{array}$ \\
\hline 1018.7 & 284.7 & 1.278 \\
1201.0 & 467.0 & 1.4453 \\
1265.0 & 531.0 & 1.50872 \\
1304.9 & 570.9 & 1.54168 \\
1371.0 & 637.0 & 1.60158 \\
1421.0 & 687.0 & 1.64138 \\
\hline
\end{tabular}

SSL = seismic depth below sea level, SSF = seismic depth below seafloor, TWT = two-way traveltime. 
Table T4. Time-depth relationship, Site U1420.

\begin{tabular}{|c|c|c|c|c|c|c|c|c|c|c|c|c|c|c|}
\hline $\begin{array}{l}\text { TWT } \\
\text { (ms) }\end{array}$ & $\begin{array}{c}\text { Depth } \\
\text { SSL } \\
(\mathrm{m})\end{array}$ & $\begin{array}{c}\text { Depth } \\
\text { SSF } \\
(\mathrm{m})\end{array}$ & $\begin{array}{l}\text { TWT } \\
\text { (ms) }\end{array}$ & $\begin{array}{l}\text { Depth } \\
\text { SSL } \\
(\mathrm{m})\end{array}$ & $\begin{array}{l}\text { Depth } \\
\text { SSF } \\
(\mathrm{m})\end{array}$ & $\begin{array}{l}\text { TWT } \\
\text { (ms) }\end{array}$ & $\begin{array}{l}\text { Depth } \\
\text { SSL } \\
(\mathrm{m})\end{array}$ & $\begin{array}{c}\text { Depth } \\
\text { SSF } \\
(\mathrm{m})\end{array}$ & $\begin{array}{l}\text { TWT } \\
\text { (ms) }\end{array}$ & $\begin{array}{l}\text { Depth } \\
\text { SSL } \\
(\mathrm{m})\end{array}$ & $\begin{array}{c}\text { Depth } \\
\text { SSF } \\
(\mathrm{m})\end{array}$ & $\begin{array}{l}\text { TWT } \\
\text { (ms) }\end{array}$ & $\begin{array}{l}\text { Depth } \\
\text { SSL } \\
(\mathrm{m})\end{array}$ & $\begin{array}{c}\text { Depth } \\
\text { SSF } \\
(\mathrm{m})\end{array}$ \\
\hline 329.29 & 255 & -4 & 564.72 & 495 & 236 & 804.2 & 735 & 476 & 1050.04 & 975 & 716 & 1307.47 & 1215 & 956 \\
\hline 335.54 & 260 & 1 & 569.19 & 500 & 241 & 809.59 & 740 & 481 & 1055.02 & 980 & 721 & 1313.9 & 1220 & 961 \\
\hline 341.29 & 265 & 6 & 573.64 & 505 & 246 & 814.93 & 745 & 486 & 1060.03 & 985 & 726 & 1320.26 & 1225 & 966 \\
\hline 347.01 & 270 & 11 & 578.1 & 510 & 251 & 820.23 & 750 & 491 & 1065.04 & 990 & 731 & 1326.53 & 1230 & 971 \\
\hline 352.68 & 275 & 16 & 582.55 & 515 & 256 & 825.48 & 755 & 496 & 1070.08 & 995 & 736 & 1332.74 & 1235 & 976 \\
\hline 358.33 & 280 & 21 & 587.03 & 520 & 261 & 830.69 & 760 & 501 & 1075.15 & 1000 & 741 & 1338.88 & 1240 & 981 \\
\hline 363.97 & 285 & 26 & 591.52 & 525 & 266 & 835.84 & 765 & 506 & 1080.24 & 1005 & 746 & 1345 & 1245 & 986 \\
\hline 369.55 & 290 & 31 & 596.06 & 530 & 271 & 840.95 & 770 & 511 & 1085.35 & 1010 & 751 & 1351.09 & 1250 & 991 \\
\hline 375.11 & 295 & 36 & 600.59 & 535 & 276 & 846.02 & 775 & 516 & 1090.5 & 1015 & 756 & 1357.17 & 1255 & 996 \\
\hline 380.63 & 300 & 41 & 605.14 & 540 & 281 & 851.06 & 780 & 521 & 1095.67 & 1020 & 761 & 1363.22 & 1260 & 1001 \\
\hline 386.13 & 305 & 46 & 609.71 & 545 & 286 & 856.1 & 785 & 526 & 1100.86 & 1025 & 766 & 1369.24 & 1265 & 1006 \\
\hline 391.59 & 310 & 51 & 614.29 & 550 & 291 & 861.14 & 790 & 531 & 1105.99 & 1030 & 771 & 1375.24 & 1270 & 1011 \\
\hline 397.01 & 315 & 56 & 618.88 & 555 & 296 & 866.23 & 795 & 536 & 1111.02 & 1035 & 776 & 1381.24 & 1275 & 1016 \\
\hline 402.4 & 320 & 61 & 623.5 & 560 & 301 & 871.39 & 800 & 541 & 1116.13 & 1040 & 781 & 1387.24 & 1280 & 1021 \\
\hline 407.75 & 325 & 66 & 628.13 & 565 & 306 & 876.68 & 805 & 546 & 1121.52 & 1045 & 786 & 1393.24 & 1285 & 1026 \\
\hline 413.07 & 330 & 71 & 632.78 & 570 & 311 & 882.28 & 810 & 551 & 1127.35 & 1050 & 791 & 1399.24 & 1290 & 1031 \\
\hline 418.35 & 335 & 76 & 637.46 & 575 & 316 & 888.33 & 815 & 556 & 1133.05 & 1055 & 796 & 1405.24 & 1295 & 1036 \\
\hline 423.58 & 340 & 81 & 642.15 & 580 & 321 & 894.4 & 820 & 561 & 1138.39 & 1060 & 801 & 1411.24 & 1300 & 1041 \\
\hline 428.79 & 345 & 86 & 646.88 & 585 & 326 & 900.23 & 825 & 566 & 1143.6 & 1065 & 806 & 1417.24 & 1305 & 1046 \\
\hline 433.94 & 350 & 91 & 651.62 & 590 & 331 & 905.92 & 830 & 571 & 1148.87 & 1070 & 811 & 1423.24 & 1310 & 1051 \\
\hline 439.03 & 355 & 96 & 656.4 & 595 & 336 & 911.57 & 835 & 576 & 1154.21 & 1075 & 816 & 1429.24 & 1315 & 1056 \\
\hline 444.06 & 360 & 101 & 661.2 & 600 & 341 & 917.21 & 840 & 581 & 1159.58 & 1080 & 821 & 1435.24 & 1320 & 1061 \\
\hline 449.09 & 365 & 106 & 666.03 & 605 & 346 & 922.81 & 845 & 586 & 1164.89 & 1085 & 826 & 1441.24 & 1325 & 1066 \\
\hline 454.13 & 370 & 111 & 670.89 & 610 & 351 & 928.26 & 850 & 591 & 1170.4 & 1090 & 831 & 1447.24 & 1330 & 1071 \\
\hline 459.16 & 375 & 116 & 675.78 & 615 & 356 & 933.5 & 855 & 596 & 1176.06 & 1095 & 836 & 1453.24 & 1335 & 1076 \\
\hline 464.19 & 380 & 121 & 680.7 & 620 & 361 & 938.63 & 860 & 601 & 1181.15 & 1100 & 841 & 1459.24 & 1340 & 1081 \\
\hline 469.21 & 385 & 126 & 685.66 & 625 & 366 & 943.66 & 865 & 606 & 1186.03 & 1105 & 846 & 1465.24 & 1345 & 1086 \\
\hline 474.54 & 390 & 131 & 690.65 & 630 & 371 & 948.54 & 870 & 611 & 1191.4 & 1110 & 851 & 1471.24 & 1350 & 1091 \\
\hline 479.93 & 395 & 136 & 695.67 & 635 & 376 & 953.48 & 875 & 616 & 1196.81 & 1115 & 856 & 1477.24 & 1355 & 1096 \\
\hline 484.94 & 400 & 141 & 700.74 & 640 & 381 & 958.44 & 880 & 621 & 1202 & 1120 & 861 & 1483.24 & 1360 & 1101 \\
\hline 489.43 & 405 & 146 & 705.83 & 645 & 386 & 963.44 & 885 & 626 & 1207.1 & 1125 & 866 & 1489.24 & 1365 & 1106 \\
\hline 493.64 & 410 & 151 & 710.98 & 650 & 391 & 968.59 & 890 & 631 & 1212.51 & 1130 & 871 & 1495.24 & 1370 & 1111 \\
\hline 497.83 & 415 & 156 & 716.15 & 655 & 396 & 973.66 & 895 & 636 & 1218.14 & 1135 & 876 & 1501.24 & 1375 & 1116 \\
\hline 502.01 & 420 & 161 & 721.36 & 660 & 401 & 978.59 & 900 & 641 & 1223.02 & 1140 & 881 & 1507.24 & 1380 & 1121 \\
\hline 506.11 & 425 & 166 & 726.62 & 665 & 406 & 983.51 & 905 & 646 & 1227.89 & 1145 & 886 & 1513.24 & 1385 & 1126 \\
\hline 510.06 & 430 & 171 & 731.93 & 670 & 411 & 988.53 & 910 & 651 & 1233.4 & 1150 & 891 & 1519.24 & 1390 & 1131 \\
\hline 513.71 & 435 & 176 & 737.27 & 675 & 416 & 993.62 & 915 & 656 & 1239.15 & 1155 & 896 & 1525.24 & 1395 & 1136 \\
\hline 517.26 & 440 & 181 & 742.65 & 680 & 421 & 998.58 & 920 & 661 & 1244.65 & 1160 & 901 & 1531.24 & 1400 & 1141 \\
\hline 520.86 & 445 & 186 & 748.08 & 685 & 426 & 1003.24 & 925 & 666 & 1249.98 & 1165 & 906 & 1537.24 & 1405 & 1146 \\
\hline 524.59 & 450 & 191 & 753.56 & 690 & 431 & 1007.58 & 930 & 671 & 1255.27 & 1170 & 911 & 1543.24 & 1410 & 1151 \\
\hline 528.56 & 455 & 196 & 759.08 & 695 & 436 & 1011.76 & 935 & 676 & 1260.75 & 1175 & 916 & 1549.24 & 1415 & 1156 \\
\hline 532.65 & 460 & 201 & 764.64 & 700 & 441 & 1016.01 & 940 & 681 & 1266.6 & 1180 & 921 & 1555.24 & 1420 & 1161 \\
\hline 536.88 & 465 & 206 & 770.26 & 705 & 446 & 1020.48 & 945 & 686 & 1272.66 & 1185 & 926 & & & \\
\hline 541.62 & 470 & 211 & 775.91 & 710 & 451 & 1025.22 & 950 & 691 & 1278.61 & 1190 & 931 & & & \\
\hline 546.24 & 475 & 216 & 781.62 & 715 & 456 & 1030.23 & 955 & 696 & 1284.37 & 1195 & 936 & & & \\
\hline 550.93 & 480 & 221 & 787.34 & 720 & 461 & 1035.2 & 960 & 701 & 1290.08 & 1200 & 941 & & & \\
\hline 555.58 & 485 & 226 & 793.05 & 725 & 466 & 1040.14 & 965 & 706 & 1295.57 & 1205 & 946 & & & \\
\hline 560.15 & 490 & 231 & 798.7 & 730 & 471 & 1045.09 & 970 & 711 & 1301.28 & 1210 & 951 & & & \\
\hline
\end{tabular}

Time-depth relationship is interpolated for deeper than $\sim 1260 \mathrm{~m}$ seismic depth below sea level (SSL). SSF = seismic depth below seafloor. 